ARTICLE

Received 30 Dec 2015 | Accepted 23 Sep 2016 | Published 4 Nov $2016 \quad$ DOl: 10.1038/ncomms13326 OPEN

\title{
Rad18-dependent SUMOylation of human specialized DNA polymerase eta is required to prevent under-replicated DNA
}

Emmanuelle Despras1,2,3, Méghane Sittewelle ${ }^{1,2,3}$, Caroline Pouvelle $e^{1,2,3}$, Noémie Delrieu 1,2,3, Agnès M. Cordonnier ${ }^{4} \&$ Patricia L. Kannouche $e^{1,2,3}$

Translesion polymerase eta ( $\mathrm{pol} \eta$ ) was characterized for its ability to replicate ultravioletinduced DNA lesions that stall replicative polymerases, a process promoted by Rad18-dependent PCNA mono-ubiquitination. Recent findings have shown that pol $\eta$ also acts at intrinsically difficult to replicate sequences. However, the molecular mechanisms that regulate its access to these loci remain elusive. Here, we uncover that poln travels with replication forks during unchallenged S phase and this requires its SUMOylation on K163. Abrogation of poln SUMOylation results in replication defects in response to mild replication stress, leading to chromosome fragments in mitosis and damage transmission to daughter cells. Rad18 plays a pivotal role, independently of its ubiquitin ligase activity, acting as a molecular bridge between pol $\eta$ and the PIAS1 SUMO ligase to promote poln SUMOylation. Our results provide the first evidence that SUMOylation represents a new way to target poln to replication forks, independent of the Rad18-mediated PCNA ubiquitination, thereby preventing under-replicated DNA.

\footnotetext{
${ }^{1}$ Univ Paris-Sud, Laboratory Genetic stability and Oncogenesis, Equipe Labellisée La Ligue Contre Le Cancer, Villejuif 94805, France. ${ }^{2}$ CNRS-UMR 8200, Villejuif 94805, France. ${ }^{3}$ Gustave Roussy Cancer Campus, Villejuif 94805, France. ${ }^{4}$ CNRS-UMR 7242, Biotechnologie et Signalisation Cellulaire, Université de Strasbourg, Ecole Supérieure de Biotechnologie, Illkirch 67412, France. Correspondence and requests for materials should be addressed to E.D. (email: emmanuelle.despras@gustaveroussy.fr) or to P.L.K. (email: patricia.kannouche@gustaveroussy.fr).
} 
$\mathrm{D}$ NA polymerase eta (poln) belongs to the Y family of specialized DNA polymerases, best characterized for their capacity to replicate DNA damages that block the progression of replicative DNA polymerases, a process called translesion synthesis (TLS) ${ }^{1}$. Poln is particularly efficient and accurate on the most abundant damage induced by ultraviolet light, the cyclobutane thymine dimer (TT-CPD $)^{2,3}$ and hereditary mutations in the $P O L H$ gene are responsible for the skin cancerprone xeroderma pigmentosum variant (XPV) syndrome, highlighting the importance of TLS for genome stability. However, pol $\eta$, like other TLS polymerases, is highly errorprone on undamaged templates and its access to DNA is tightly regulated through several mechanisms. For instance, monoubiquitination of PCNA (Ub-PCNA) by the Rad18/Rad6 complex at stalled replication forks allows specific recruitment of pol $\eta$ at damaged sites thanks to the cooperation of its PCNA- and ubiquitin-interacting motifs ${ }^{4-6}$. Direct interaction with Rad18 and phosphorylation also promote ultraviolet lesion bypass and cell survival ${ }^{7-10}$, whereas extraction from chromatin by the segregase valosin containing protein (VCP) and proteasomal degradation, presumably relying on ubiquitination of the TLS polymerase, were proposed to limit the extent of poln-dependent synthesis after bypass and the subsequent mutagenesis ${ }^{11-13}$.

Recently, a new function of pol $\eta$ at intrinsically difficult to replicate DNA loci was proposed in human cells ${ }^{14,15}$. Paragons of these loci are the common fragile sites (CFSs), which are DNA regions exquisitely prone to breakage upon mild replication stress, for instance when replicative polymerases are slowed down by a low dose of aphidicolin (APH). Incomplete replication of these loci generates DNA intermediates that can pass through mitosis, where they can be cleaved by endonucleases, generating gaps or breaks on metaphasic chromosomes ${ }^{16,17}$ or form ultra-fine bridges resolved by the Bloom pathway ${ }^{18,19}$. Stigmata of incomplete DNA replication can also be observed in the G1 daughter cells by the formation of 53BP1 nuclear bodies (53BP1 NBs), which are proposed to shield the transmitted DNA damages until repair ${ }^{20,21}$. Pol $\eta$ localizes at CFSs upon mild replication stress and is more efficient than the replicative pol $\delta$ to replicate CFS sequences able to adopt non-B conformations in vitro. Moreover, APH-challenged poln-deficient cells show delayed completion of CFS replication, higher number of gaps and breaks in metaphase and accumulation of 53BP1 NBs compared with wild-type (WT) cells ${ }^{14,15}$. Pol $\eta$ was therefore proposed to participate in the timely completion of CFS replication, thereby preventing the persistence of under-replicated DNA in mitosis and CFS instability. As most of the knowledge on poln regulation comes from analysis of its canonical function at ultraviolet damage, it is not yet clear if this new lesion-independent function shares the same regulatory mechanisms.

Here, we show that, unexpectedly, pol $\eta$ travels with replication forks during unperturbed $S$ phase and that this relies on SUMOylation of the TLS polymerase on lysine K163. Abrogation of this post-translational modification (PTM) mimics the phenotype of poln-deficient cells in response to low doses of $\mathrm{APH}$, whereas it has a marginal impact after ultraviolet radiation. Rad18, independently of its ubiquitin ligase activity, promotes poln SUMOylation by facilitating its interaction with its SUMO ligase PIAS1 and is required for poln function at difficult to replicate loci. Permanently SUMOylated poln overcomes the need for Rad18 and PIAS1 in this process. Altogether, these data unravel a new way to recruit pol $\eta$ to replication forks, especially relevant during lesion-independent replication stress.

\section{Results}

poly and Rad18 travel with replication forks. The discovery of pol $\eta$ involvement in the replication of difficult to replicate DNA loci suggests that the TLS polymerase can be recruited to replication forks in absence of DNA damage. It is known for long that overexpressed pol $\eta$ forms nuclear foci that co-localize with replication foci (RF) in a subset of untreated $S$ phase cells ${ }^{22}$ but the localization of endogenous poln remains elusive. We therefore performed iPOND experiment (isolation of proteins on nascent DNA ${ }^{23}$ in unchallenged MRC5-V1 fibroblasts. Nascent strands were pulse-labelled with the thymine analogue 5-ethynyl-2'-deoxyuridine (EdU) followed by conjugation of biotin on EdU and purification by streptavidin pull-down (Fig. 1a). Proteins associated to labelled DNA were analysed by western blot. Poln was retrieved in the sample harvested immediately after the pulse but lost in the thymidine-chased sample (Fig. 1b). This behaviour is similar to the one of known replisome components, PCNA and the catalytic subunit of


poln travels with replication forks during unperturbed $S$ phase. Interestingly, we found that Rad18, one of its regulators, also associated with nascent DNA.

SUMOylation on K163 drives Poly to nascent DNA. To better understand how pol $\eta$ is recruited to replication forks, we made the assumption that it could rely on PTMs of the polymerase. We focused on the small ubiquitin-like modifier (SUMO) pathway, as it was shown that SUMOylated proteins are enriched at replication forks ${ }^{24}$ and that SUMOylation was proposed to protect the C. elegans ortholog of poln (polh-1) from degradation during DNA damage bypass ${ }^{25}$.

Therefore, to examine if human pol $\eta$ is a SUMO target, 293FT cells were co-transfected with plasmids coding for WT poln $\left(\mathrm{pol} \eta^{\mathrm{WT}}\right.$ ) and His-tagged SUMO1 or SUMO3. SUMOylated proteins were purified on nickel $(\mathrm{Ni})$ beads in denaturing conditions and analysed by western blot using three different anti-pol $\eta$ antibodies (Fig. 2a). All the antibodies detected a slower migrating band in the pull-down, preferentially in the presence of His-SUMO3 (arrow). This band was no longer detected upon overexpression of the SUMO protease SENP1 but not of a catalytically dead SENP1 mutant (Fig. 2b), confirming that it is a SUMOylated species and suggesting that SENP1 is responsible for pol $\eta$ deSUMOylation. SUMO-modified pol $\eta$ was also detected


Figure 1 | Human poln is recruited to replication forks during unchallenged S phase. (a) Scheme for the iPOND procedure: MRC5-V1 cells were pulse-labelled with EdU for $10 \mathrm{~min}$. Cells were then crosslinked and harvested immediately or after a $1 \mathrm{~h}$ thymidine chase to allow replication forks moving away from the labelled DNA. Biotin was conjugated to EdU by click chemistry before cell lysis and chromatin fragmentation. EdU-containing DNA and associated proteins were purified on streptavidin beads. (b) Input and EdU-associated proteins (iPOND) were analysed by western blot using the indicated antibodies. No EdU: negative control processed as described in a but without EdU incorporation. 
a

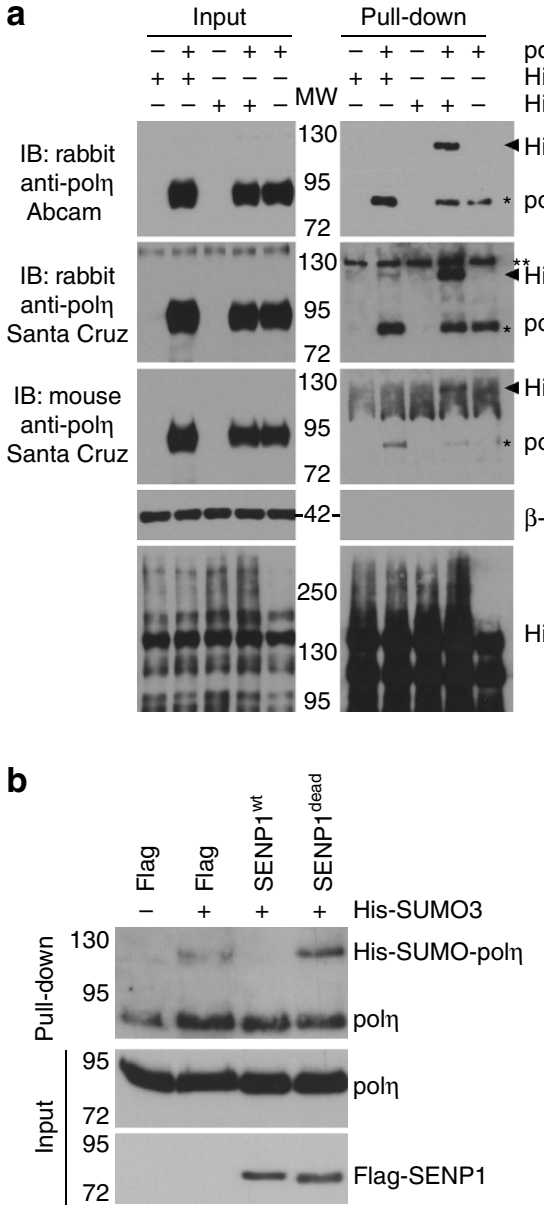

C

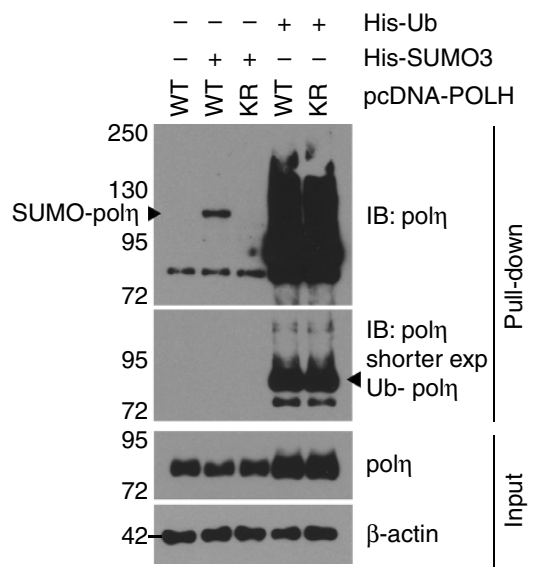

d



e

Homo sapiens Pan troglodytes Bos taurus

Mus musculus

Xenopus laevis

Danio rerio

Gallus gallus

Drosophila melanogaster

Caenorhabditis elegans

Sacharomyces cerevisiae

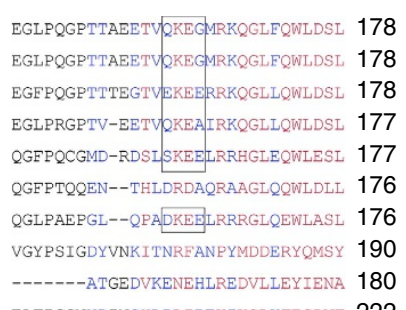

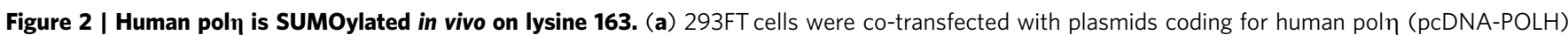
and His-tagged SUMO1 or SUMO3 (His-SUMO1, His-SUMO3). Empty His and pcDNA vectors were used as controls. Cells were lysed 24 h after transfection under denaturing conditions. SUMOylated proteins were recovered on Nickel ( $\mathrm{Ni}$ ) beads. Total extracts (input) and $\mathrm{Ni}$ eluates (pull-down) were analysed by western blot using three different antibodies raised against pol $\eta$ in different species. *unspecific binding of unmodified pol $\eta$ to Ni beads;

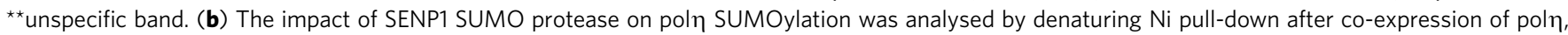
His-SUMO3 and WT or catalytically dead Flag-SENP1. (c) 293FT cells were co-transfected with plasmids coding for WT poln or a mutant in which lysine 163 was replaced by arginine (KR) and His-tagged SUMO3 or His-tagged ubiquitin (Ub). Poln modifications were analysed as in a. See also Supplementary Fig. 1d for His immunoblotting. (d) Schematic representation of human poln. NLS, nuclear localization signal; PAD, polymerase associated domain (little finger); PIP, PCNA-interacting peptide; UBZ, ubiquitin-binding zinc finger. (e) Sequence alignment of poln homologues in various species. The SUMOylation site is highlighted in boxes.

with Flag-poln using an anti-Flag antibody (Supplementary Fig. 1a). The increase of the molecular weight of the polymerase ( $\sim 40 \mathrm{kDa})$ suggests that SUMOylated pol $\eta$ may contain more than one SUMO moiety. Mutation of K11 of SUMO3 to arginine (R), which prevents the formation of SUMO chains ${ }^{26}$, did not modify the apparent size of the modification (Supplementary Fig. 1b), showing that it is mono-SUMOylation(s).

The two Ks SUMOylated in Caenorhabditis elegans polh-1 are conserved in human pol $\eta$; however, their mutations did not prevent its SUMOylation (Supplementary Fig. 1c). To identify the SUMO acceptor site(s), we performed in silico analysis with three SUMOylation site-prediction software programs (SUMOplot http://www.abgent.com/sumoplot, seeSUMO ${ }^{27}$ and SUMOsp ${ }^{28}$ ) and tested $\mathrm{K}$ to $\mathrm{R}$ mutants of the common predicted sites. We identified K163 as the SUMO acceptor site using denaturing $\mathrm{Ni}$ pull-down (Fig. 2c and Supplementary Fig. 1d). To confirm our findings, we co-expressed green fluorescent protein

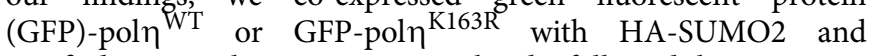
purified GFP-pol $\eta$ on GFP-trap beads followed by extensive washes in stringent denaturing conditions. A slower migrating band was detected by both anti-pol $\eta$ and anti-HA antibodies only with GFP-poln ${ }^{\mathrm{WT}}$ (Supplementary Fig. 1e). K163R mutation did not affect pol $\eta$ ubiquitination (Fig. 2c and Supplementary Fig. 1d), in agreement with previous results mapping the ubiquitination sites in the C-terminus of the polymerase ${ }^{29}$ and suggesting that SUMOylation is not a prerequisite for poln mono-ubiquitination.

K163 lies in the catalytic domain of poln, in the back of the palm domain, and the SUMOylation site is conserved in most vertebrates, at the exclusion of zebrafish (Fig. 2d,e and Supplementary Fig. 1f, ref. 30). To explore if SUMOylation can impact on the intrinsic activity of the polymerase, we generated, in addition to pol $\eta^{\mathrm{K} 163 \mathrm{R}}$, a mimetic of constitutively SUMOylated pol $\eta$ (pol $\eta^{\mathrm{SUMO}}$ ) by inserting the sequence of SUMO2 in place of K163 (Fig. 3a and Methods). Pol $\eta^{\mathrm{K} 163 \mathrm{R}}$ and pol $\eta^{\text {SUMO }}$ were fully competent for replication of undamaged DNA and for TT-CPD bypass in vitro (Fig. 3b-d). Hence, both non-SUMOylable and constitutively SUMOylated pol $\eta$ retained full intrinsic polymerase activity and the introduced mutations do not alter the conformation of poln catalytic site. 
a

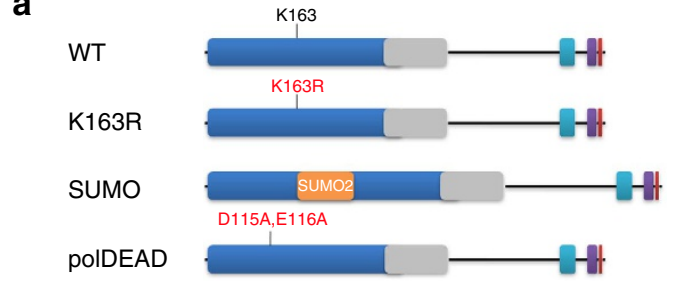

b



C



d



Figure 3 | K163R and SUMO poln retain full catalytic activity in vitro. (a) Schematic representations of the poln mutants used in the study. In

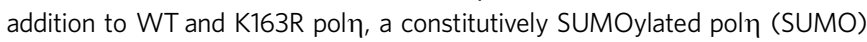
was constructed by inserting the sequence of SUMO2 in place of K163. A track of 7 glycines ( $\mathrm{G}$ ) was added before SUMO2 to confer flexibility. The C-terminal di-G motif of SUMO2 was mutated to alanines to prevent cleavage by the SENPs. Two constructs were generated: SUMOa contains the atg of SUMO2, whereas it was mutated to G in SUMOb. A catalytically inactive poln (poIDEAD) was used as a negative control. (b) The indicated proteins were produced in rabbit reticulocytes and their catalytic activity was analysed by primer extension on a circular single-stranded undamaged template (representative gel). (c) Polymerase activity is shown as a percentage of the activity measured for WT pol $\eta$ in 10-min reaction (mean \pm s.d. of three independent experiments). (d) For analysis of TLS efficiency, equal amounts of the in vitro translated proteins were introduced in an XPV cell extract. Bypass of a single TT-CPD (TLS) was assessed as described in Methods. L-1: fragment elongated up to one nucleotide before the lesion.
We next investigated the biological significance of pol $\eta$ SUMOylation by establishing XPV cells stably expressing pol $\eta^{\mathrm{K} 163 \mathrm{R}}$ or pol $\eta^{\mathrm{SUMO}}$. Both mutants localized in the nucleus and we confirmed that pol $\eta^{\mathrm{K} 163 \mathrm{R}}$ is not SUMOylated in these conditions (Supplementary Fig. 2). We first examined by immunofluorescence the capacity of these mutants to form spontaneous foci. Cells were pre-extracted with a detergent before fixation to unravel the fraction of pol $\eta$ associated to nuclear structures and PCNA was used as a marker of $\mathrm{RF}^{6,22}$. Only $10 \%$ of pol $\eta^{\mathrm{K} 163 \mathrm{R}} \mathrm{S}$ phase cells presented spontaneous pol $\eta$ foci, compared with $40 \%$ for pol $\eta^{\mathrm{WT}}$ (Fig. 4a,c). Moreover, pol $\eta^{\mathrm{K} 163 \mathrm{R}}$ foci were fainter although total pol $\eta^{\mathrm{K} 163 \mathrm{R}}$ amounts were similar to that of pol $\eta^{\mathrm{WT}}$ (Supplementary Figs 2 and 4a). In contrast, poln $\eta^{\text {SUMO }}$ was fully proficient in spontaneous focus formation (Fig. 4b,d).

To determine if the impairment of spontaneous focus formation reflects a defect of pol $\eta^{\mathrm{K} 163 \mathrm{R}}$ recruitment to replication forks, we performed iPOND in our stable cell lines. Whereas both poln $\eta^{\mathrm{WT}}$ and pol $\eta^{\mathrm{SUMO}}$ were found at replication forks, the K163R mutation abolished pol $\eta$ recruitment to nascent DNA (Fig. 4e,f). In situ proximity ligation assay (PLA) between pol $\eta$ and neo-synthesized DNA confirmed this finding (Supplementary Fig. 3). Importantly, although MRC5-V1 and poln WT cells showed specific PLA signals compared with XPV cells, only background amplification was detected in pol $\eta^{\mathrm{K} 163 \mathrm{R}}$ cells, despite a 3-4-fold overexpression compared with endogenous pol $\eta$ level (Supplementary Fig. 2a). Altogether, these results strongly suggest that poln association with the replication machinery in unchallenged conditions required its SUMOylation on K163.

SUMO-pol $\eta$ increases after replication stress. If SUMOylation on K163 constitutes a means to recruit poln to replication forks, one obvious question is how this PTM impacts on the canonical and non-canonical functions of pol $\eta$ during $S$ phase. To answer this, we first determined the consequence of replication stress on pol $\eta$ SUMOylation. Pol $\eta^{\mathrm{WT}}$ cells were transfected with His-SUMO3 and exposed to ultraviolet-C or to low doses of replication inhibitors APH and hydroxyurea. Denaturing Ni pulldowns showed that SUMOylated poln was readily observed in mock-treated cells and that its level increased after both DNA lesion-dependent or -independent replication stress (Fig. 5a,b).

As previously observed ${ }^{6,22}$, ultraviolet- $C$ exposure led to the accumulation of pol $\eta^{\mathrm{WT}}$ in RF (Fig. $5 c, d$ ). Pol $\eta^{\mathrm{K} 163 \mathrm{R}}$ was also able to relocalize to $\mathrm{RF}$ after ultraviolet-C, although in only $45 \%$ of S-phase cells versus $70 \%$ for pol $\eta^{\mathrm{WT}}$ and with a fainter staining (Fig. 5c,d and Supplementary Fig. 4a,b). In spite of this defect, poln ${ }^{\mathrm{K} 163 \mathrm{R}}$ was able to complement the ultraviolet sensitivity of XPV cells and pol $\eta^{\mathrm{K} 163 \mathrm{R}}$ cells were not further sensitized by addition of a low concentration of caffeine, a characteristic feature of XPV cells used for diagnostic ${ }^{31}$ (Fig. 5e). Accordingly, pol $\eta^{\mathrm{K} 163 \mathrm{R}}$ prevented the accumulation of single-strand DNA during replication of ultraviolet-damaged $\mathrm{DNA}^{32}$ as efficiently as pol $\eta^{\mathrm{WT}}$ (Supplementary Fig. 5). However, pol $\eta^{\mathrm{K} 163 \mathrm{R}}$ cells were significantly more sensitive than poln ${ }^{\mathrm{WT}}$ cells at a higher ultraviolet-C dose (Supplementary Fig. 4c), suggesting that poln SUMOylation can contribute to its recruitment at ultraviolet-stalled forks. Interestingly, pol $\eta$ SUMO cells displayed WT sensitivity to ultraviolet-C. However, we observed a slight but reproducible sensitization by caffeine at a high ultraviolet- $\mathrm{C}$ dose (Supplementary Fig. $4 \mathrm{~d}-\mathrm{f}$ ), suggesting that deSUMOylation is required to ensure efficient pol $\eta$ function at ultraviolet-damaged sites.

Abrogation of poln SUMOylation leads to under-replicated DNA. In contrast to what was observed after ultraviolet, XPV and pol $\eta^{\mathrm{K} 163 \mathrm{R}}$ cells treated with a low dose of $\mathrm{APH}$ experienced 
a

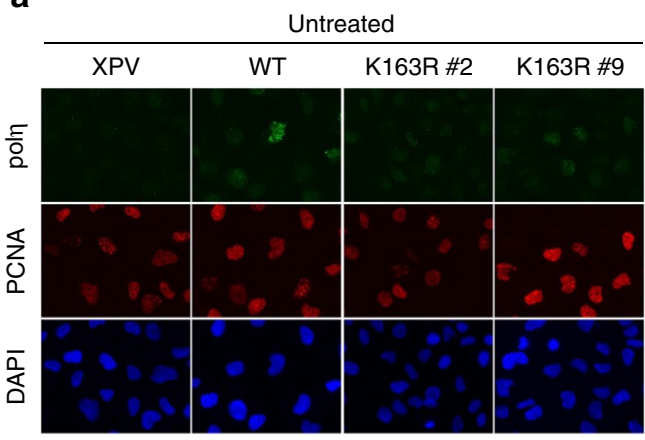

b

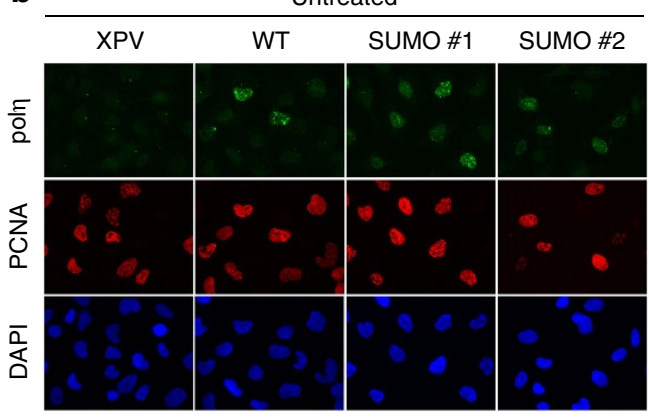

C



e

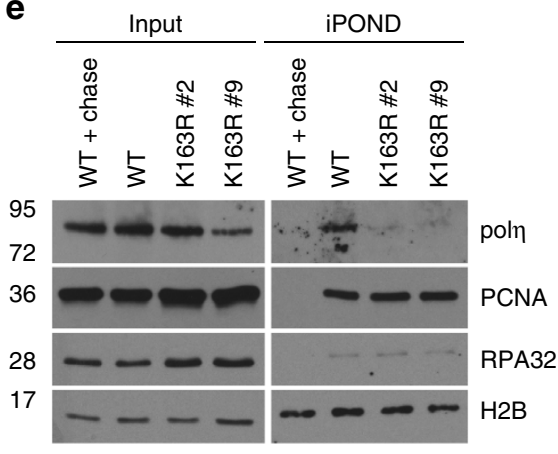



f

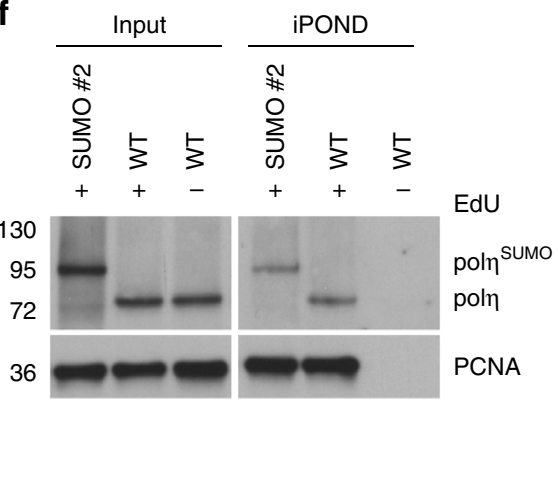

Figure 4 | SUMOylation of poly is crucial for its recruitment at replication forks during unperturbed S phase. (a,b) Untreated XPV cells stably expressing pol $\eta^{\mathrm{WT}}$, pol $\eta^{\mathrm{K} 163 \mathrm{R}}$ or pol $\eta^{\mathrm{SUMO}}$ were fixed after extraction of soluble proteins and immunostained with pol $\eta$ and PCNA antibodies. Parental XPV cells were used as a negative control for pol $\eta$ staining. Representative images are shown (magnification $\times 63$ ). (c,d) The proportion of PCNA-positive cells presenting pol $\eta$ foci was assessed in three independent experiments (mean \pm s.d.). At least 200 cells were counted per condition and experiment. $(\mathbf{e}, \mathbf{f})$ iPOND experiments were performed as described in Fig. 1.

similar replication problems, as evidenced by increased recruitment of RPA32 on chromatin compared with poln ${ }^{\mathrm{WT}}$ cells (Supplementary Fig. 5). Moreover, APH did not increase pol $\eta^{\mathrm{K} 163 \mathrm{R}}$ association to RF (Fig. 6a,b and Supplementary Fig. 6a), indicating that mild replicative stress is not sufficient per se to restore pol $\eta^{\mathrm{K} 163 \mathrm{R}}$ focus formation.

We then assumed that SUMOylation of poln on K163 could be required to prevent the persistence of under-replicated DNA at difficult to replicate loci ${ }^{14,15}$. To test this hypothesis, we first analysed the transmission of DNA damage to the daughter cells in the next G1 phase following APH exposure. XPV cells displayed a higher number of 53BP1 NBs per G1 cell compared with pol $\eta^{\mathrm{WT}}$ cells, as already shown ${ }^{14}$. This defect was not corrected by the stable expression of pol $\eta^{\mathrm{K} 163 \mathrm{R}}$ (Fig. 6c,d and Supplementary Fig. 6b). Interestingly, we found that poln depletion in MRC5-V1 cells lead to segregation defects upon APH exposure with an increased number of anaphases presenting lagging chromosome fragments, in majority devoid of centromeric protein CENPA (Fig. 6e-g). This phenotype, evocative of increased chromosomal breaks, was also observed in XPV cells compared with poln ${ }^{\mathrm{WT}}$ cells and was not rescued by pol $\eta^{\text {K163R }}$ expression (Fig. 6h). Moreover, pol $\eta^{\text {K163R }}$ and XPV cells showed similar slightly higher sensitivity to a low dose of $\mathrm{APH}$ (Fig. 6i). In agreement with its efficient recruitment to replication forks, pol $\eta^{\text {SUMO }}$ complemented the APH-induced defects of XPV cells (Supplementary Fig. 6c). However, this effect was only partial in the clone expressing the highest pol $\eta^{\text {SUMO }}$ level (\#2), suggesting that overexpressed permanently SUMOylated poln may interfere with the correct processing of some replication intermediates.
We then asked whether pol $\eta$ SUMOylation impairment could affect genetic stability without impacting on cell survival after ultraviolet. We showed that pol $\eta$ deficiency led to a dosedependent increase of anaphases with chromosome fragments after ultraviolet irradiation (Supplementary Fig. 7). However, both pol $\eta^{\mathrm{K} 163 \mathrm{R}}$ and pol $\eta^{\text {SUMO }}$ were able to correct this phenotype, again arguing for a minor role of poln SUMOylation at ultraviolet-induced DNA lesions.

Altogether, these results indicate that SUMOylation on K163 is required for poln recruitment at replication forks and its subsequent involvement in preventing persistence of underreplicated DNA at difficult to replicate loci. Abrogation of this PTM mimics pol $\eta$ deficiency in this specific function.

Poln recruitment on nascent DNA requires PIAS1 SUMO ligase. To have a deeper insight into the regulation of poln SUMOylation, we then aimed to identify the SUMO ligase responsible for this modification. In C. elegans, polh-1 is SUMOylated by GEI-17 (ref. 25), which belongs to the PIAS family of E3 SUMO ligases that counts four members in human cells (PIAS1-4). Although the SUMOylation sites are not conserved from worm to human, we asked whether the E3 SUMO ligase of human poln could belong to this family. We showed that poln co-immunoprecipitated with both PIAS1 and PIAS4 (Fig. 7a,b), two SUMO ligases already involved in the DNA damage response ${ }^{33-35}$. However, only PIAS1 depletion impaired poln SUMOylation (Fig. 7c and Supplementary Fig. 8a). Conversely, PIAS1 overexpression enhanced poln SUMOylation in a K163-dependent manner (Fig. 7d). These 
a

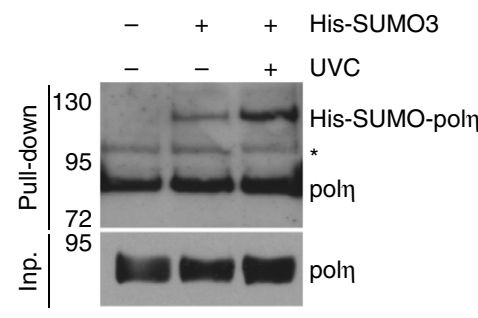

b



C

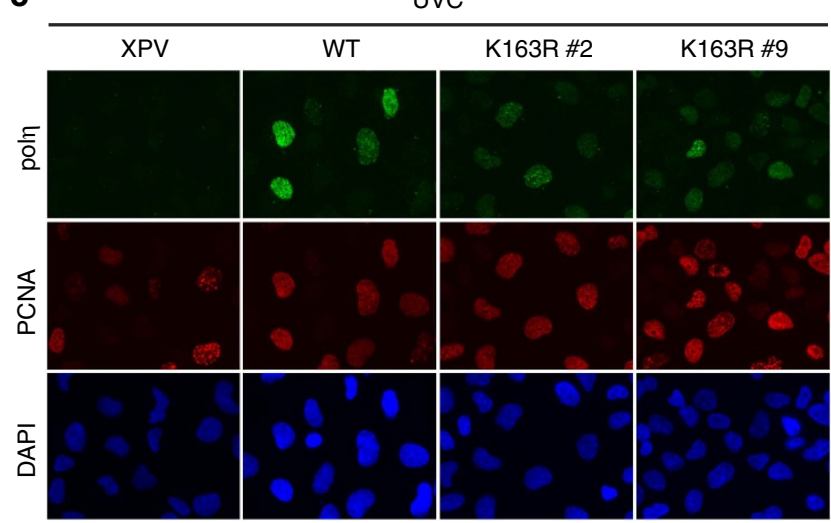

d

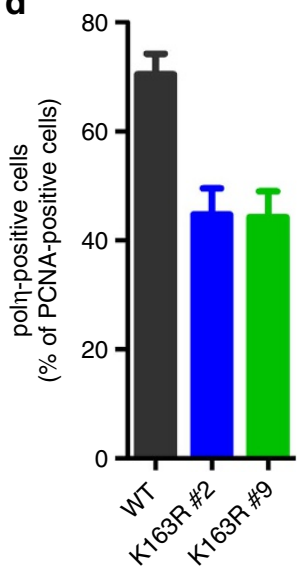

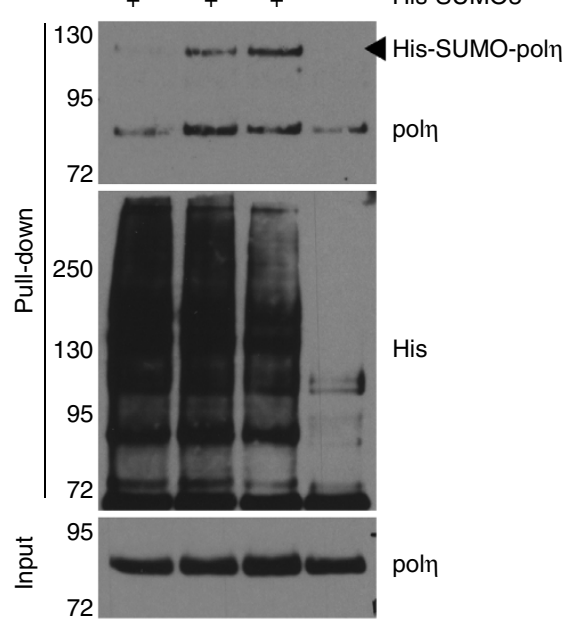



Figure 5 | SUMOylation of poln increases after replication stress while has a minor impact on poln function at ultraviolet-induced DNA lesions. $(\mathbf{a}, \mathbf{b})$ XPV cells stably expressing poln WT were transfected with His-SUMO3. $24 \mathrm{~h}$ after transfection, cells were irradiated at $20 \mathrm{~J} \mathrm{~m}{ }^{-2}$ and incubated for $6 \mathrm{~h}$ (a) or treated with $0.3 \mu \mathrm{M} \mathrm{APH}$ or $0.2 \mathrm{mM}$ hydroxyurea $(\mathrm{HU})$ for $24 \mathrm{~h}(\mathbf{b})$ before performing denaturing Ni pull-down. Bound material was analysed by immunoblotting using the indicated antibodies. *unspecific band. (c,d) XPV cells stably expressing poln WT or pol $\eta^{\mathrm{K} 163 \mathrm{R}}$ were irradiated with ultraviolet-C $\left(20 \mathrm{~J} \mathrm{~m}^{-2}\right.$ ), incubated for $6 \mathrm{~h}$ and processed as described in Fig. 4a-d. (e) XPV, poln ${ }^{\mathrm{WT}}$ and pol $\eta^{\mathrm{K} 163 \mathrm{R}}$ cells were irradiated with ultraviolet-C at the indicated doses and incubated for $72 \mathrm{~h}$ in medium supplemented or not with $0.38 \mathrm{mM}$ caffeine. Living cells were counted in the presence of trypan blue. Data are expressed as the percentage of living cells compared with mock-treated cells (mean \pm s.d. of four independent experiments).

results indicate that PIAS1 is the E3 SUMO ligase of human poln on K163.

PLA between pol $\eta$ and EdU showed that depletion of PIAS1 impaired the proximity of poln with newly synthesized DNA in both poln ${ }^{\mathrm{WT}}$ and MRC5-V1 cells but had no significant impact on the recruitment of pol $\eta^{\text {SUMO }}$ (Fig. 7e-g and Supplementary Fig. 8b). Hence, recruitment of poln to nascent strands requires PIAS1-mediated SUMOylation of the polymerase and all the above data strongly suggest that this modification occurred on K163.

Rad18 promotes PIAS1-mediated poln SUMOylation. Given that poln interacts constitutively with Rad18 (ref. 8), that both proteins travel with replication forks (Fig. 1b) and that depletion of Rad18 impaired pol $\eta$ recruitment to nascent DNA (Supplementary Fig. 8b), we investigated if Rad18 is involved in poln SUMOylation. Depletion of Rad18 using different specific siRNAs strongly impaired poln SUMOylation (Fig. 8a), indicating that Rad18 facilitates this PTM. To determine which functional domains of Rad18 act in this pathway, we analysed the impact of overexpression of various Rad18 mutants on poln
SUMOylation (Fig. 8b-d). Rad18 ${ }^{\mathrm{WT}}$ promoted both K163dependent and -independent SUMOylation events (see the red and black lines, respectively, in Fig. 8c). Interestingly, this was independent of its ubiquitin ligase activity $\left(\operatorname{Rad} 18^{\mathrm{C} 28 \mathrm{~F}}\right.$ ) or its SAF-A/B, Acinus and PIAS (SAP) domain (Rad18 ${ }^{S^{*} P^{*}}$ ), but depends on its ubiquitin-binding zinc finger (UBZ) motif $\left(\operatorname{Rad} 18^{\mathrm{C} 207 \mathrm{~F}}\right)$. Noteworthy, K163-independent poln SUMOylation was markedly increased upon proteasome inhibition (Supplementary Fig. 9a), suggesting that other SUMOylation events may drive pol $\eta$ to degradation.

Rad18 directly interacts with the last 158 aa of poln via its poln-binding domain (BD), which was mapped between amino acids (aa) 401 and 445 (ref. 8). To determine if this direct interaction is required for poln SUMOylation, we first used a C-terminally truncated pol $\eta\left(\right.$ pol $\left.\eta^{1-642}\right)$ and showed that it was impaired in both SUMOylation and association to Rad18 (Supplementary Fig. 9b). We next generated Rad18 truncation mutants lacking the poln $\mathrm{BD}\left(\operatorname{Rad} 18^{1-409}\right)$ or the last 50 aa $\left(\operatorname{Rad} 18^{1-460}\right)$, which contain a nuclear localization signal (NLS) between aa 488 and 494 (ref. 36). In addition, the NLS of SV40 $\mathrm{T}$ antigen was added to the N-terminus of the protein to restore nuclear localization of these mutants $\left(\operatorname{Rad} 18^{\text {nls1-409 }}\right.$ and 
Rad $\left.18^{\text {nls1-460}}\right)$. Disruption of the poln BD abrogated poln SUMOylation, independently of the presence of a NLS (Fig. 8e,f). Rad18 $8^{\text {nls1-460 }}$ was able to promote poln SUMOylation as efficiently as $\operatorname{Rad} 18^{\mathrm{WT}}$, indicating that the last 50 aa of Rad18 were not required. Interestingly, Rad $18^{1-460}$ was able to interact with poln (Supplementary Fig. 9c) but failed to promote its SUMOylation, indicating that the nuclear localization of Rad18 is important. Altogether, these results point out that direct a

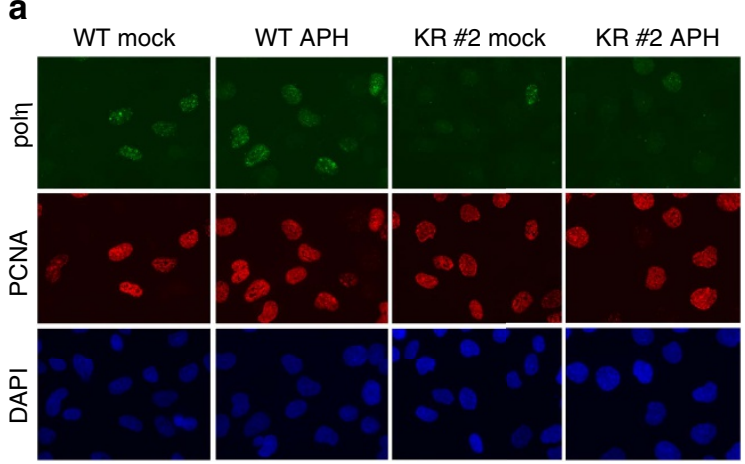

C

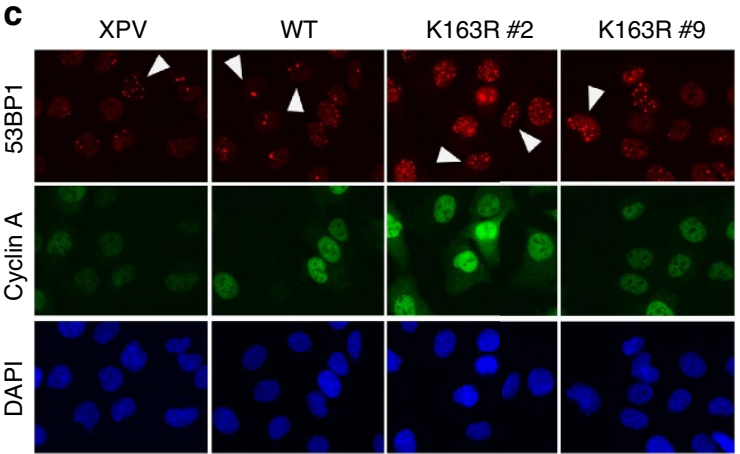

e
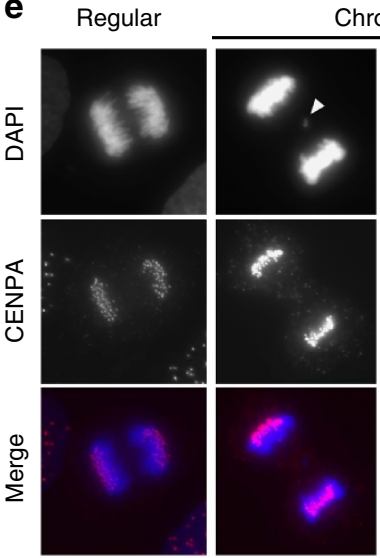

hromosome fragments

h

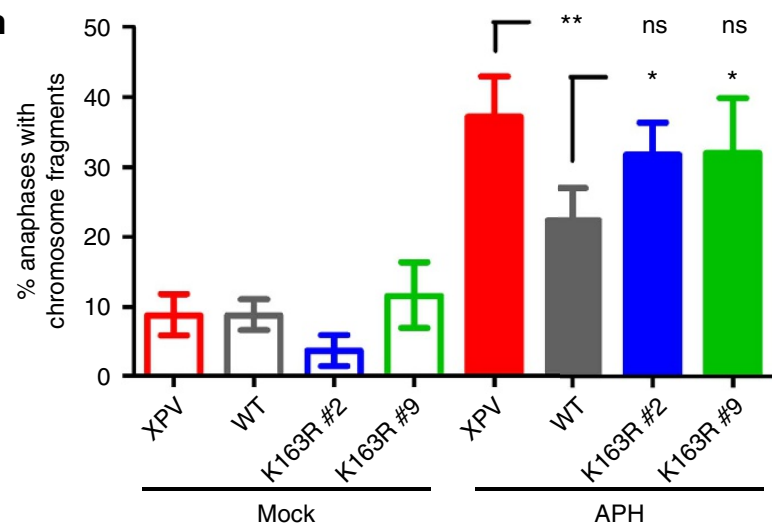

b
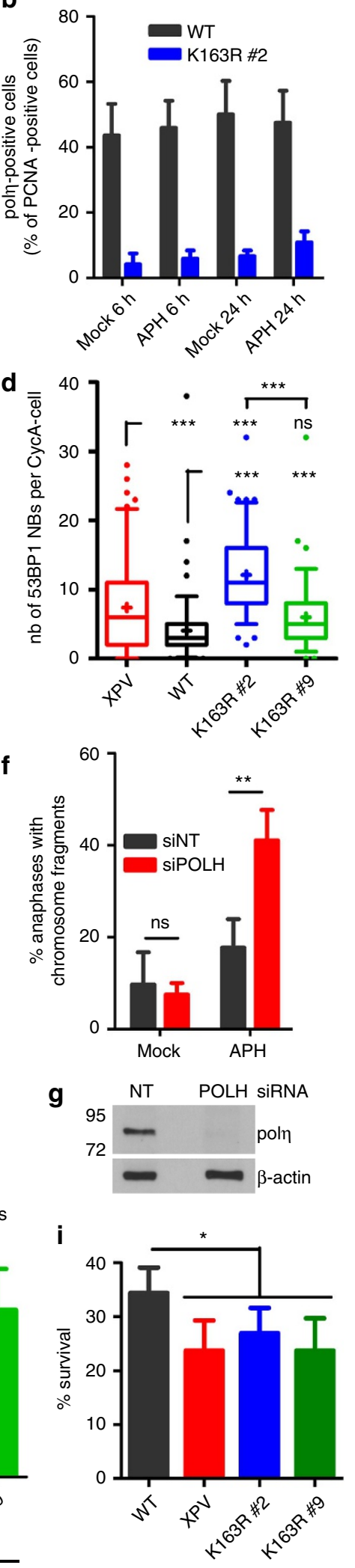
interaction between pol $\eta$ and $\operatorname{Rad} 18$ is essential to promote poln SUMOylation in the nucleus, in agreement with the known localization of PIAS1 (ref. 37).

As a matter of fact, we showed that $\operatorname{Rad} 18$ interacted with PIAS1 (Fig. 8g). This required a functional NLS but was independent of $\operatorname{Rad} 18$ association with poln (Supplementary Fig. 9d). In contrast, depletion of Rad18 weakened the interaction between pol $\eta$ and PIAS1 (Fig. 8h), indicating that Rad18 may target poln to PIAS1 and/or bridge the two proteins together to allow efficient poln SUMOylation. Interestingly, poln $\eta^{\mathrm{SUMO}}$ overcame the need for Rad18 for its recruitment on nascent DNA (Supplementary Fig. 9e). Altogether, our data show that direct interaction between poln and $\operatorname{Rad} 18$ promotes pol $\eta$ SUMOylation and pol $\eta$ recruitment to nascent DNA, independently of Rad18-mediated PCNA ubiquitination.

SUMO-poln and Rad18 act in the same pathway after APH. We next showed that depletion of Rad18 increased the number of anaphases with chromosome fragments (Fig. 9a and Supplementary Fig. 10a) and the number of 53BP1 NBs in the next G1 (Supplementary Fig. 10b) after APH, in a similar manner than poln depletion. Simultaneous depletion of the two proteins did not further aggravate these defects. We confirmed this in HCT116 cells, where depletion of pol $\eta$ in WT cells increased the level of chromosomal fragmentation after APH to the one observed in mock- or poln-depleted $R A D 18^{-/-}$cells (Fig. 9b and Supplementary Fig. 10c). Altogether, these data suggest an epistatic relationship between pol $\eta$ and $\operatorname{Rad} 18$ in response to mild replication stress.

We then generated cell populations expressing WT or mutated Rad18 fused to GFP. Endogenous Rad18 was depleted using a siRNA directed against the $3^{\prime}$-untranslated region ( $3^{\prime}$-UTR) of the mRNA (siR18 $3^{\prime}$-UTR) and cells were treated with a low dose of $\mathrm{APH}$ for $24 \mathrm{~h}$ before scoring anaphases with chromosome fragments in GFP-positive cells. Interestingly, both Rad18 WT and ubiquitin ligase deficient $\operatorname{Rad} 18^{\mathrm{C} 28 \mathrm{~F}}$ were able to rescue the segregation defects observed in endogenous Rad18-depleted cells (Fig. 9c and Supplementary Fig. 10d). This suggests that ubiquitination of PCNA by $\operatorname{Rad} 18$ is not required in response to mild replicative stress, unlike what was previously observed after ultraviolet ${ }^{38,39}$. In agreement with that, depletion of pol $\eta$ in cells expressing a non-ubiquitinable PCNA mutant (PCNA $^{\mathrm{K} 164 \mathrm{R}}$ ) led to increased chromosome fragmentation after APH (Supplementary Fig. 10e). In contrast, analysis of cells expressing Rad18 ${ }^{\mathrm{C} 207 \mathrm{~F}}$ showed that integrity of the UBZ motif is critical for this pathway (Fig. 9d and Supplementary Fig. 10d). These phenotypes correlate with the impact of the

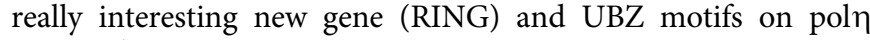
SUMOylation.

Finally, we showed that depletion of Rad18, and to a lesser extent of PIAS1, increased the number of anaphases with chromosome fragments after APH in pol $\mathrm{WT}^{\mathrm{WT}}$ but not in poln SUMO expressing cells, which demonstrates that constitutively SUMOylated poln overcomes the need for Rad18 and PIAS1 to act during mild replication stress (Fig. 9e,f). Interestingly, PIAS1 depletion significantly decreased the APH-induced mitotic defects in XPV cells, suggesting that PIAS1 may also be involved in the formation or processing of these fragments when the activity of pol $\eta$ is compromised.

We propose that Rad18 promotes poln SUMOylation by acting as a platform between the TLS polymerase and its SUMO ligase PIAS1, allowing poln recruitment to replication forks and prevention of under-replicating DNA in response to mild replication stress.

\section{Discussion}

The regulation of poln access to replicating damaged DNA has been under close scrutiny since its discovery, with two underlying issues: (i) how is pol $\eta$ recruited to damaged sites, where its TLS activity is required, and (ii) how is TLS restricted to avoid mutagenesis on undamaged DNA? The recent discovery that pol $\eta$ also acts at intrinsically difficult to replicate loci ${ }^{14,15}$ modifies the way of apprehending TLS polymerase transactions on DNA. In this study, we uncovered a new mechanism, involving the SUMO pathway and Rad18, which regulates this non-canonical function of human poln during $S$ phase.

Our results showed that SUMOylation of poln on K163 is required for its recruitment to RF during unperturbed $S$ phase or under low replication stress and, to a lesser extent, after ultraviolet-C irradiation. This PTM is particularly important in response to $\mathrm{APH}$, preventing accumulation of ssDNA during $\mathrm{S}$ phase, genetic instability and cellular sensitivity. In contrast, it is largely dispensable for the efficient bypass of ultraviolet-induced lesions. Furthermore, SUMOylation of poln is promoted by direct interaction with $\operatorname{Rad} 18$ but independent of its ubiquitin ligase activity. We therefore propose that pol $\eta$ is differentially regulated in response to DNA lesions and to intrinsic replication fork barriers (Fig. 10). During unperturbed $S$ phase or under mild replication stress, when the amounts of Ub-PCNA are low, PIAS1-mediated SUMOylation on K163 targets or retains pol $\eta$ in the vicinity of replication forks encountering difficult to replicate sequences, such as non-B DNA, promoting the timely completion of their replication. After ultraviolet exposure, pol $\eta$ relocalizes to virtually all RF, where its accumulation mainly relies on PCNA ubiquitination, as already described ${ }^{4,6}$. Our results highlight a

\footnotetext{
Figure 6 | Abrogation of poln SUMOylation leads to replication defects in response to mild replication stress. (a,b) XPV cells stably expressing poln WT or pol $\eta^{\mathrm{K} 163 \mathrm{R}}$ were treated with $0.3 \mu \mathrm{M} \mathrm{APH}$ for 6 or $24 \mathrm{~h}$ and processed as described in Fig. $4 \mathrm{a}-\mathrm{d}$. The a panel shows representative images after $24 \mathrm{~h}$ of $\mathrm{APH}$. (c) XPV, poln ${ }^{\mathrm{WT}}$ and pol $\eta^{\mathrm{K} 163 \mathrm{R}}$ cells were treated with $0.3 \mu \mathrm{M} \mathrm{APH}$ for $26 \mathrm{~h}$ before fixation and were immunostained with $53 \mathrm{BP} 1$ and cyclin $\mathrm{A}$ antibodies. Representative images are shown (magnification $\times 63$ ). (d) The number of 53BP1 nuclear bodies (53BP1 NBs) was assessed in at least 100 cyclin A-negative cells (G1 cells, white arrows). Experiment was repeated three times, giving similar results. The distribution of 53BP1 NBs in G1 for one experiment is shown in a box-plot with 5-95 percentile whiskers (see also Supplementary Fig. 6b). ns: not significant; ${ }^{\star \star \star} P<0.001$ (Mann-Whitney test). (e) MRC5-V1 cells were transfected with a siRNA directed against pol $\eta$ mRNA (siPOLH) or a non-targeting control (siNT) $48 \mathrm{~h}$ before exposure to $0.15 \mu \mathrm{M}$ $\mathrm{APH}$ for $24 \mathrm{~h}$. Cells were fixed and centromeres were detected by immunostaining of CENPA. DNA was visualized using DAPI. Representative images of a regular anaphase and anaphases presenting lagging chromosome fragments are shown (magnification $\times 100$ ). Most of the fragments lack CENPA staining (white arrows). CENPA can occasionally be found in lagging fragments (yellow arrow). (f) The percentage of anaphases presenting chromosome fragments was assessed in four independent experiments (mean \pm s.d., $n=50$ for each experiment). (g) Western blot confirming the efficiency of pol $\eta$ depletion. (h) The proportion of aberrant anaphases was also assessed in XPV cells and XPV cells stably expressing WT or K163R poln $24 \mathrm{~h}$ after treatment with $0.3 \mu \mathrm{M} \mathrm{APH}$ (mean \pm s.d. of five independent experiments, $n=50$ for each experiment). (i) XPV, poln ${ }^{\mathrm{WT}}$ and pol $\eta^{\mathrm{K} 163 \mathrm{R}}$ cells were treated with $0.3 \mu \mathrm{M}$ $\mathrm{APH}$ for $72 \mathrm{~h}$ and surviving fraction was expressed as a percentage of mock-treated cells (mean $\pm \mathrm{s}$.d. of four independent experiments). ns: not significant, ${ }^{\star} P<0.05,{ }^{\star \star} P<0.01$ ( $t$-test).
} 
a

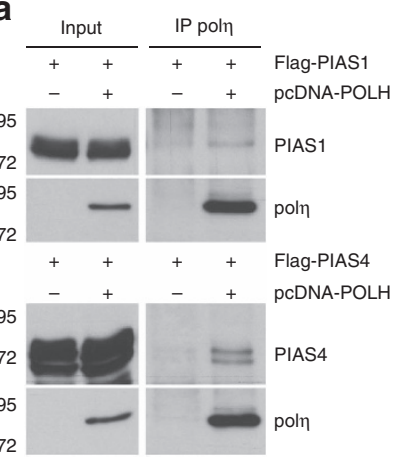

b



C

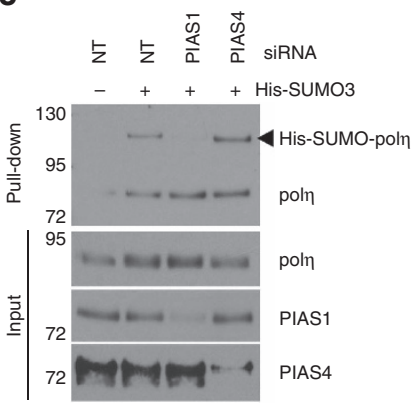

d

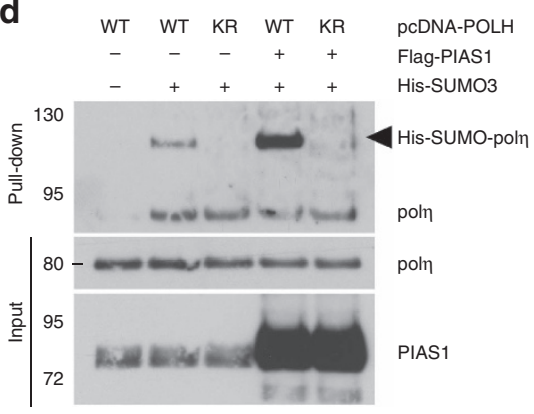

$\mathbf{f}$

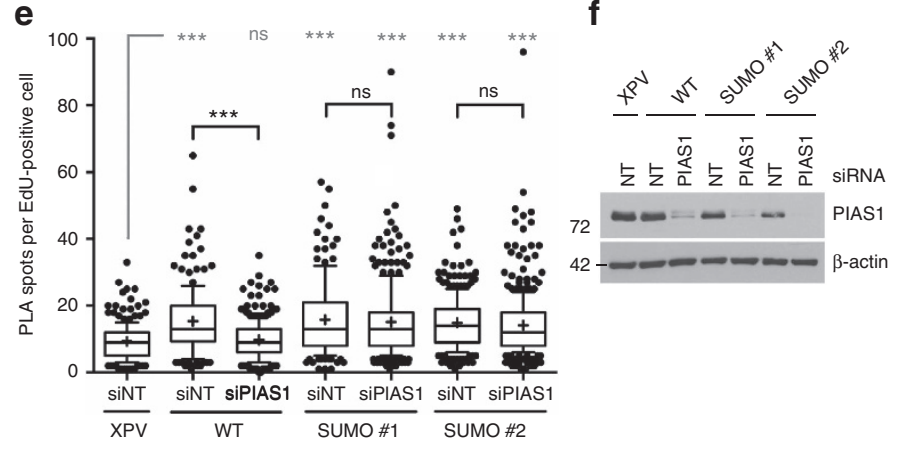

g

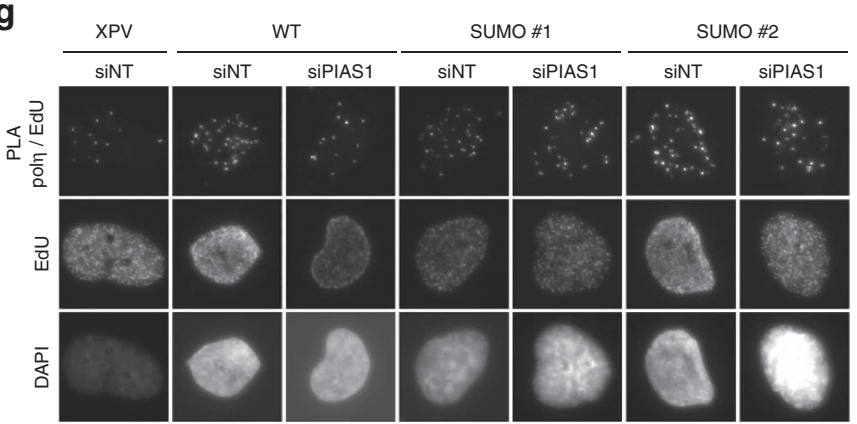

Figure 7 | Pol $\boldsymbol{\eta}$ is SUMOylated in a PIAS1-dependent manner. (a) 293FT cells were transfected with pcDNA-POLH and Flag-PIAS1 or Flag-PIAS4 and co-immunoprecipitations were performed using an anti-pol $\eta$ antibody. (b) Reversed immunoprecipitations were performed with an anti-Flag antibody. (c) $293 \mathrm{FT}$ cells were transfected with the indicated siRNAs $24 \mathrm{~h}$ before co-transfection of plasmids expressing pol $\eta$ and His-SUMO3. Denaturing Ni pull-down was carried out as described in Fig. 2. (d) WT or K163R (KR) poln was co-expressed in 293FT cells with His-SUMO3 and Flag or Flag-PIAS1 and cells were processed as in c. (e) XPV, poln ${ }^{\mathrm{WT}}$ and pol $\eta^{\mathrm{SUMO}}$ cells were transfected with non-targeting or PIAS1 siRNAs. Nascent DNA was pulse-labelled with EdU for $5 \mathrm{~min}$ and cells were pre-extracted and fixed. Biotin was conjugated to EdU by click chemistry in order to perform an in situ PLA between pol $\eta$ and EdU-biotin. EdU-biotin was then counterstained using a fluorescent secondary antibody. The distribution of the number of PLA spots per EdU-positive cells was assessed in two independent experiments. One representative experiment is shown in box-plot with 10-90 percentile whiskers $\left(n>150\right.$, ns: not significant, ${ }^{\star \star \star} P<0.001$, Mann-Whitney test). (f) Western blot showing the efficiency of PIAS1 depletion. (g) Representative images of the PLA experiment quantified in (e) (magnification $\times 63$ ). 
a

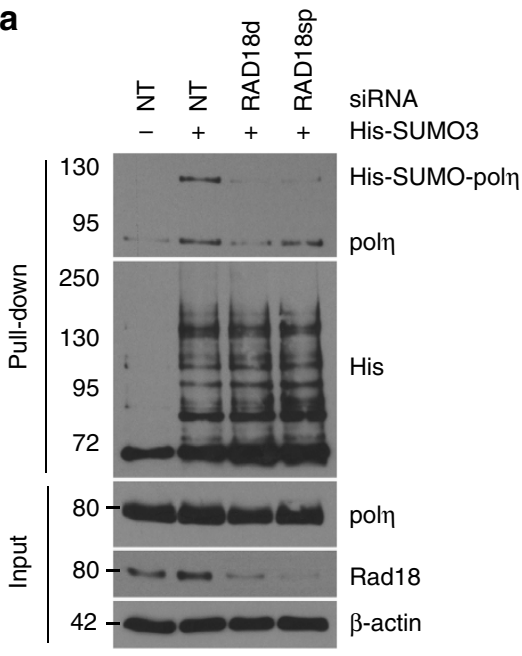

b

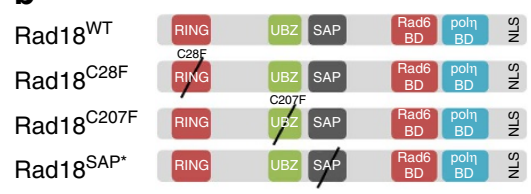



C $\quad 5 \xi \frac{9}{5} \frac{x}{\Sigma}$ pcDNA-POLH

-+++++ His-SUMO3

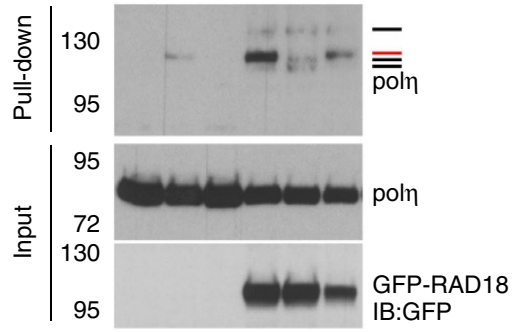

d
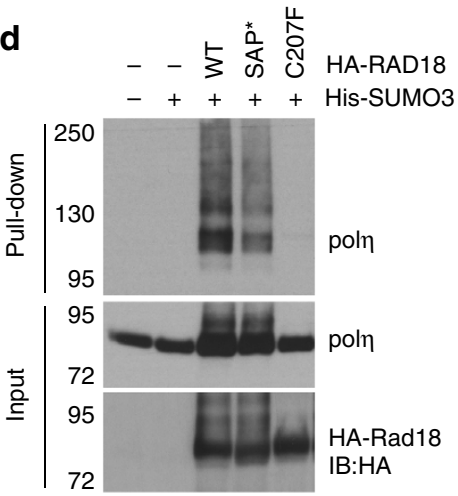

e

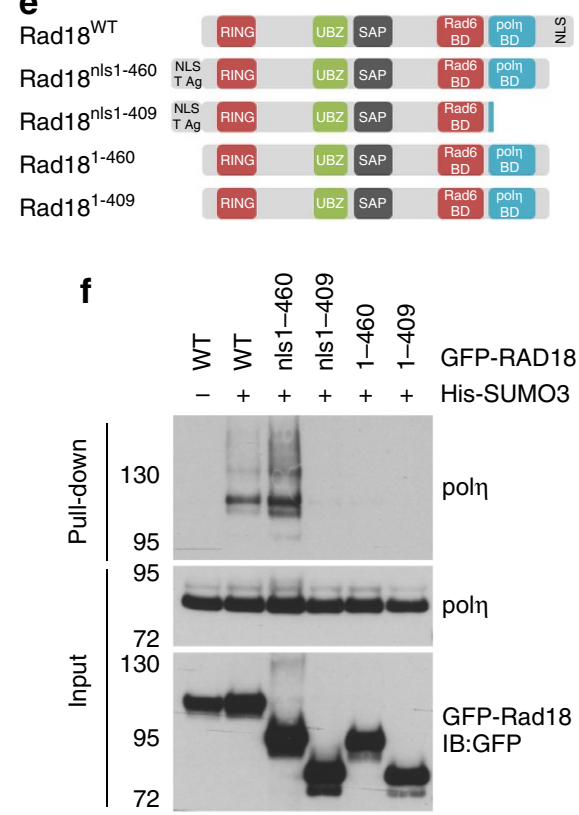

g
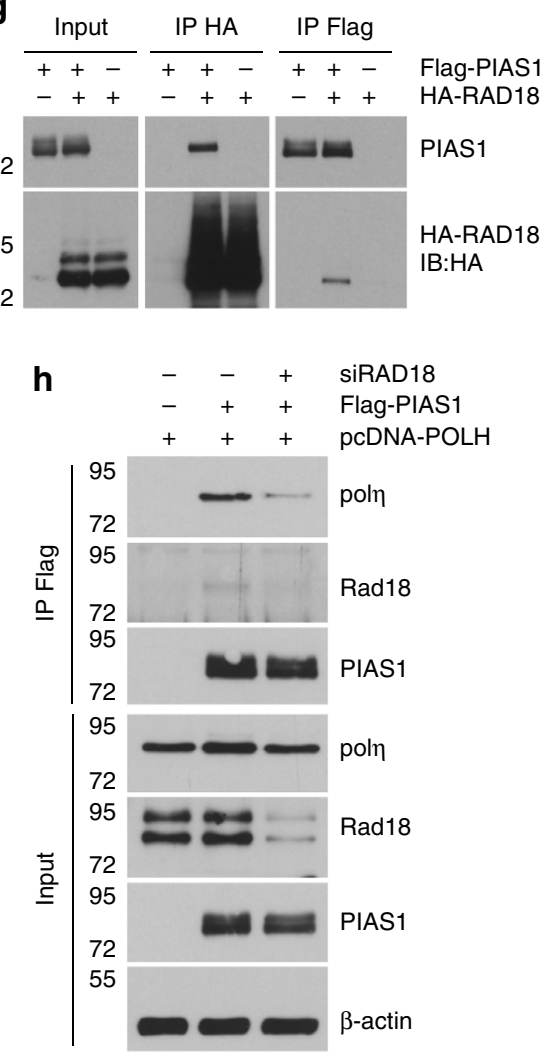

Figure 8 | Rad18 facilitates poln SUMOylation by promoting poln interaction with PIAS1 SUMO ligase. (a) $293 \mathrm{FT}$ cells were depleted of Rad18 using either a single duplex (RAD18d) or a pool of four sequences (RAD18sp) $24 \mathrm{~h}$ before co-transfection of plasmids expressing pol $\eta$ and His-SUMO3. Pol $\eta$ SUMOylation was analysed as in Fig. 2. (b) Schematic representation of the point mutations of Rad18 used in the study. RING, really interesting new gene domain conferring ubiquitin ligase activity (mutated in Rad18 ${ }^{\mathrm{C} 28 \mathrm{~F}}$ ); UBZ, ubiquitin-binding zinc finger (mutated in Rad18 $\mathrm{C} 207 \mathrm{~F}$ ); SAP, SAF-A/B, Acinus and PIAS domain (mutated in Rad18 SAP* $^{\star} 269 A, K 271 A$ ); Rad6 BD, E2-conjugating enzyme Rad6-binding domain; poln BD: poln-binding domain; NLS, nuclear localization signal. (c,d) SUMOylation of poln was assessed after overexpression of WT Rad18 or the mutants depicted in $\mathbf{b}$. Red line: SUMOylation on K163, black lines: K163-independent SUMOylation events. (e) 293FT cells were transfected with pcDNA-POLH, His-SUMO3 and various truncation mutants of GFP-RAD18 (upper panel). As Rad18 $8^{1-460}$ and Rad18 ${ }^{1-409}$ lack the C-terminal NLS, the NLS of the T antigen of SV40 (T Ag) was added to the $\mathrm{N}$-terminus of the protein (Rad18 ${ }^{\text {nls1-460 }}$ and Rad18 ${ }^{\text {nls1-409 }}$ ). (f) The impact of these truncation mutants on poln SUMOylation was compared with the one of Rad18 WT . (g) 293FT cells were co-transfected with HA-RAD18 and Flag-PIAS1 plasmids. Co-immunoprecipitations were performed using anti-HA or anti-Flag antibodies. (h) Plasmids expressing poln and Flag-PIAS1 were co-transfected in mock- or Rad18-depleted 293FT cells. The interaction between poln and PIAS1 was analysed by immunoprecipitation using an anti-Flag antibody. 
a



C



b

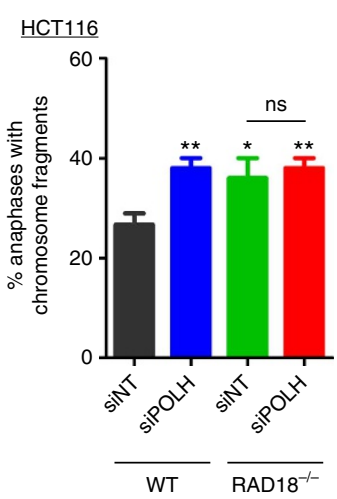

d

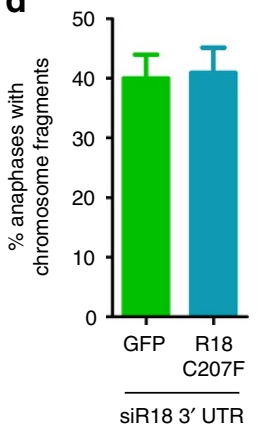

e

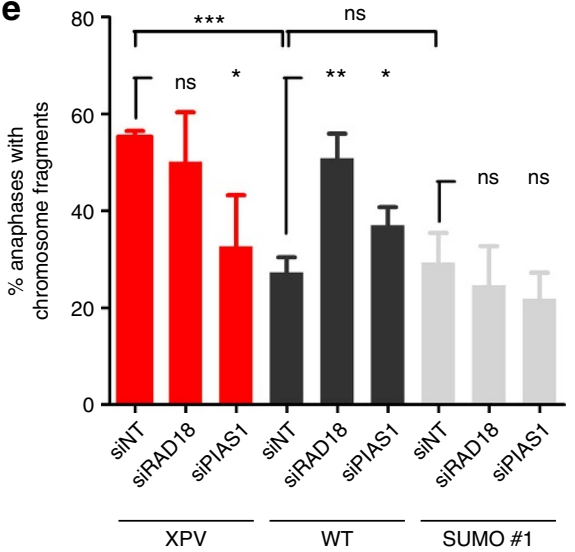

f

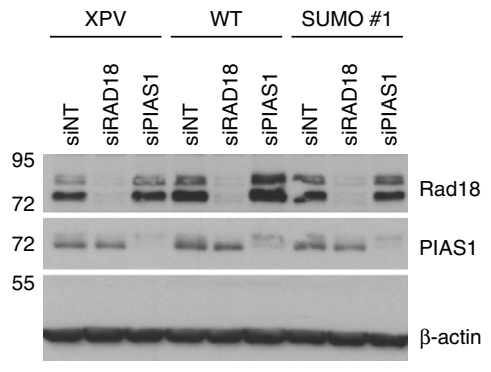

Figure 9 | Pol $\eta$ and Rad18 act in the same pathway in response to replication stress and this requires Rad18 UBZ but not its ubiquitin ligase activity. (a) MRC5-V1 cells were transfected with siRNAs directed against poln (siPOLH) and/or Rad18 (siRAD18) mRNAs $48 \mathrm{~h}$ before exposure to $0.15 \mu \mathrm{M}$ APH for $24 \mathrm{~h}$. The percentage of anaphases with chromosome fragments was scored (mean $\pm \mathrm{s}$. d. of three independent experiments, $n=50$ for each experiment). See Supplementary Fig. 10a for siRNA efficiency. (b) The percentage of anaphases with chromosome fragments was scored in poln-depleted WT or RAD18 ${ }^{-/-}$HCT116 cells $24 \mathrm{~h}$ after $0.15 \mu \mathrm{M} \mathrm{APH}$ (mean \pm s.d. of three independent experiments, $n=50$ for each experiment). See Supplementary Fig. 10c for siRNA efficiency. (c,d) MRC5-V1 cell populations expressing GFP, GFP-Rad18 WT, GFP-Rad18 ${ }^{\mathrm{C} 28 \mathrm{~F}}$ or GFP-Rad18 $207 \mathrm{~F}$ were depleted for endogenous Rad18 using a siRNA directed against the $3^{\prime}$-UTR of the mRNA (siR18 $3^{\prime}$-UTR). Cells were then treated for $24 \mathrm{~h}$ with $0.15 \mu \mathrm{M} \mathrm{APH}$ and anaphases were analysed in GFP-positive cells. Data are the mean \pm s.d. of four (c) or three (d) independent experiments. See Supplementary Fig. 10d for siRNA efficiency. (e) The impact of Rad18 or PIAS1 depletion on the chromosome fragments in anaphase was determined in $\mathrm{XPV}$, pol $\eta^{\mathrm{WT}}$ and pol $\eta^{\mathrm{SUMO}}$ cells $24 \mathrm{~h}$ after $0.3 \mu \mathrm{M} \mathrm{APH}$. Data are the mean \pm s.d. of three independent experiments $(n=50$ for each experiment). ns: not significant, ${ }^{\star} P<0.05,{ }^{\star \star} P<0.01,{ }^{\star \star \star} P P<0.001$ (t-test). (f) Western blot showing the efficiency of the siRNAs used in $\mathbf{e}$.

central role for Rad18 in the regulation of poln, as it is a key factor in both processes, which rely on distinct functional domains. Indeed Rad18, in complex with the E2 ubiquitin conjugating enzyme Rad6, is responsible for the ubiquitination of PCNA, a process requiring both its RING and SAP domains, and also directly targets pol $\eta$ to damaged sites ${ }^{8,40}$. Here, we show that Rad18 promotes poln SUMOylation in a UBZ-dependent manner by bridging pol $\eta$ and its SUMO ligase PIAS1 and shares an epistatic relationship with the TLS polymerase in response to mild replication stress. Interestingly, these latter functions do not require a functional Rad18 RING domain and therefore the associated PCNA ubiquitination. However, as other ubiquitin ligases are able to ubiquitinate PCNA ${ }^{41,42}$, we cannot formally exclude that Rad18-independent ubiquitination of PCNA participates in pol $\eta$ function at difficult to replicate DNA loci. In particular, it would be interesting to investigate the role of the E3 ubiquitin ligase CRL4 ${ }^{\mathrm{Cdt} 2}$, as it is responsible for a fraction of PCNA ubiquitination in untreated cells ${ }^{41}$. Moreover, this E3 ligase targets some PCNA-interacting proteins to degradation after ultraviolet, a mechanism required for poln focus formation ${ }^{43,44}$. As most CRL4 ${ }^{\text {Cdt2 }}$ substrates are also degraded during the course of unperturbed $\mathrm{S}$ phase, it is tempting to speculate that this clearance pathway operates as well during the replication of difficult to replicate loci.

We showed that the K163R mutation does not lead to a strong defect of ultraviolet-lesion bypass, as evidenced by cell survival experiments, lack of ssDNA accumulation in S phase and rescue of the mitotic defects observed in irradiated pol $\eta$-deficient cells. However, in agreement with the moderate impairment of focus formation after ultraviolet, pol $\eta^{\mathrm{K} 163 \mathrm{R}}$ cells display increased sensitivity to high ultraviolet doses than pol $\eta^{\mathrm{WT}}$ cells, suggesting that SUMOylation on K163 indeed also participates to the accumulation of pol $\eta$ at forks stalled by photoproducts. Recently, several studies have challenged the currently accepted model placing Ub-PCNA at the heart of TLS regulation, with data supporting Ub-PCNA independent pathway(s) for pol $\eta$ activation $^{45-47}$. We propose that SUMOylation on K163 provides an alternative way to recruit pol $\eta$ at damaged sites when PCNA ubiquitination is compromised.

Hence, although canonical and non-canonical poln functions during $S$ phase could theoretically be reconciled in a unique tolerance mechanism requiring the same stalling/recruitment/ bypass steps irrespectively of the type of fork barrier, our data argue for a differential regulation of pol $\eta$ at DNA damage and at 


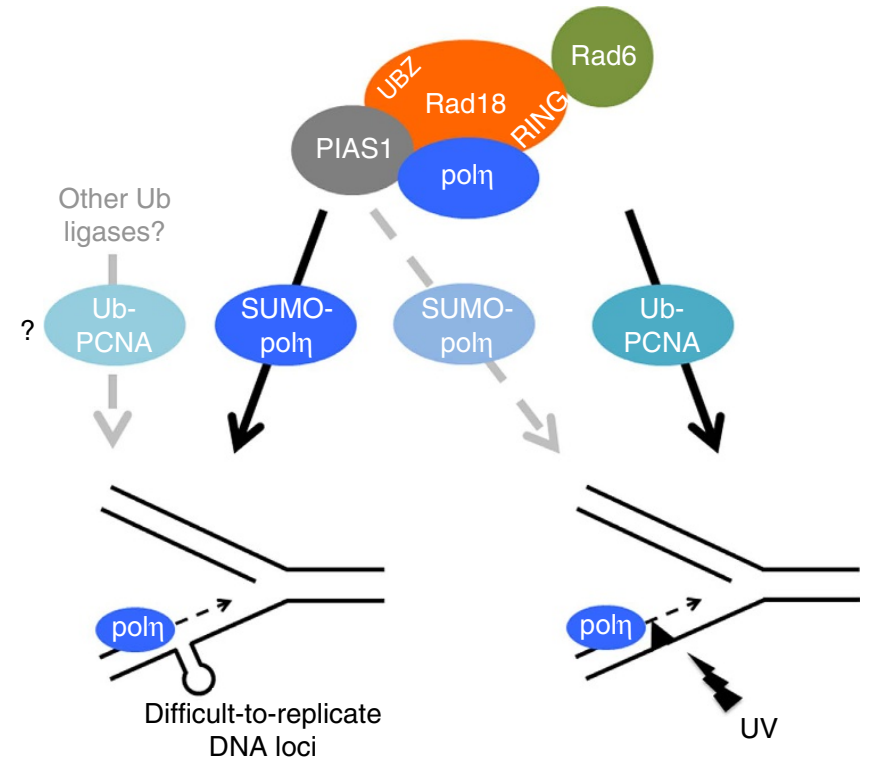

Figure 10 | A model for the dual regulation of human poly in response to ultraviolet-C lesions and at difficult to replicate DNA loci. During unperturbed $\mathrm{S}$ phase or after a low dose of $\mathrm{APH}$, SUMOylation of poln on K163 promotes its recruitment to replication forks to allow the timely completion of the replication of specific genomic regions presumably bearing non-B DNA structures. This PTM relies on the ternary complex formed by poln, Rad18 and the SUMO ligase PIAS1 and is independent of Rad18 ubiquitin ligase activity. Whether pol $\eta$ function at difficult to replicate DNA sequences also requires Rad18-independent PCNA ubiquitination remains to be established. After ultraviolet exposure, PCNA is ubiquitinated at forks stalled by photoproducts by the Rad18/Rad6 complex, which allows accumulation of pol $\eta$ at damaged sites, as already described. However, SUMOylation of poln on K163 may also contribute, to a minor extent, to the recruitment of the polymerase, constituting an alternative pathway in cells deficient in PCNA ubiquitination.

non-B DNA. We postulate that this may reflect requirement of different protein complexes or different impacts of these replication impediments on the structure of the replication intermediates, a subject that remains largely unexplored in human cells.

Using iPOND to retrieve the proteins associated with nascent DNA, we showed that pol $\eta$ and Rad18 travel with replication forks during unperturbed $S$ phase. Noteworthy, during the preparation of this manuscript, two teams also identified Rad18 as a component of the replisome ${ }^{48,49}$. Our data on poln are, to our knowledge, the first demonstration of a TLS polymerase association with protein complexes at nascent strands in unchallenged cells. This finding was rather unexpected, given the intrinsic low fidelity of the polymerase on undamaged templates. However, our observation fits well with the emerging concept of TLS polymerases involvement in the natural course of DNA replication ${ }^{50}$. Moreover, poln presence in the replisome does not necessarily imply that it actively replicates DNA, a hypothesis supported by the limited number of interaction signals

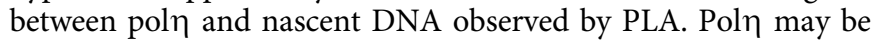
pre-recruited to rapidly cope with barriers impeding replication fork progression. Composition of the replisome varies in response to acute replication stress $s^{23,48,51}$. However, it is not yet precisely known if and how this complex is modulated in response to natural fork barriers and after mild replication stress. Therefore, it remains to be determined if pol $\eta$ and Rad18 are constitutive component of the replisome or if they are specifically found in the vicinity of forks dealing with the replication of problematic DNA regions like CFSs.

The current model implies that Rad18 is recruited on chromatin through the ssDNA formed at stalled forks and therefore its DNA-binding domain SAP is required for ultraviolet-induced PCNA ubiquitination and pol $\eta$ foci ${ }^{38,52}$. We found that poln SUMOylation and prevention of segregation defects upon APH treatment rather rely on the UBZ domain of Rad18, a motif involved in Rad18 dimerization and subnuclear localization $^{36,38,53-55}$ but dispensable for PCNA ubiquitination, poln foci formation and cell survival after ultraviolet ${ }^{36,54}$. Interestingly, the UBZ motif was shown to promote interaction of Rad18 with ubiquitinated chromatin components including histone $\mathrm{H} 2 \mathrm{~A}^{38,56}$. Hence, it may provide a way to recruit the Rad18/poln complex to the replisome, independently of fork stalling, and/or may target them to specific DNA regions.

Our results showed that association of poln with the replisome in unperturbed S phase required its PIAS1-mediated SUMOylation on K163. Interestingly, both PIAS1 and SUMOylated species are enriched on nascent $\mathrm{DNA}^{24,48}$. However, it is not yet clear if PIAS1 SUMOylates pol $\eta$ in the vicinity of replication forks, despite the fact that we demonstrated that pol $\eta$ is SUMOylated in the nucleus. As it has been reported for many other SUMOmodified proteins, the amount of SUMOylated poln is very low compared with that of the unmodified protein and only unmodified poln was detected at replication forks. SUMO conjugation can be a very transient event, yet having a prolonged impact on the target protein. The cycling model proposed to explain this apparent paradox stipulates that SUMOylation acts through cycles of conjugation/deconjugation, SUMOylation promoting an event, like the recruitment of the target to a protein complex, which can persist after SUMO clearance 57,58 . Based on this model, we hypothesize that highly

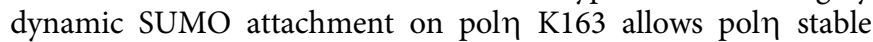
incorporation in the replisome. The factors chaperoning this process remain to be identified.

On the other hand, it is also tempting to speculate that poln SUMOylated on K163 represent the DNA elongating form of the polymerase in vivo and that its small amount precludes any detection by the current methods. According to the crystal structure of human pol $\eta$, the K163 residue is located in the back of the palm domain, in the most flexible region of the catalytic domain $^{30}$. Therefore, and in agreement with our in vitro data, it is unlikely that attachment of a SUMO moiety alters the conformation or polymerase activity of pol $\eta$. However, the fact that pol $\eta^{\mathrm{K} 163 \mathrm{R}}$ is proficient in ultraviolet lesion bypass in vivo suggests that SUMOylation is not a strict requirement for poln activity. SUMOylation on K163 might then protect poln from restrictive mechanisms during DNA synthesis, in reminiscence of what is observed in the nematode after damage ${ }^{25}$, the excessive turn-over of poln $\eta^{\mathrm{K} 163 \mathrm{R}}$ at DNA synthesis sites being partly compensated by its increased affinity for Ub-PCNA after ultraviolet.

Interestingly, pol $\eta$ was found as a putative SUMO target by mass spectrometry analysis of cells treated with the proteasome inhibitor MG132 (ref. 59), suggesting that SUMOylation may be a prerequisite for poln degradation. We confirmed this finding using denaturing $\mathrm{Ni}$ pull-down and showed that the SUMOylation events up regulated by inhibition of the proteasome are independent of K163. Therefore, SUMO pathway may fulfil two opposite roles: SUMOylation on K163 promotes pol $\eta$ function at difficult to replicate loci, whereas multiple SUMOylations on other unidentified sites mark the polymerase for proteasomal degradation. Recently, the segregase p97/VCP, associated to its adaptator Spartan/DVC1, has been shown to extract pol $\eta$ from the chromatin after lesion 
bypass $^{11,13}$. VCP mostly acts on ubiquitinated proteins, but it is now demonstrated that it can also target SUMOylated proteins ${ }^{60,61}$. Interestingly, Spartan/DVC1 has been proposed as the functional homologue of the yeast metalloprotease wss 1 (ref. 62), a partner of the yeast ortholog of VCP recently shown to bear a SUMO ligase activity ${ }^{63}$. One possibility is therefore that Spartan/DVC1 may be responsible for the SUMOylation events leading to pol $\eta$ degradation. Further investigations are required to clarify this hypothesis.

In summary, we identified a novel layer of regulation of poln to prevent under-replicated DNA at difficult to replicate loci, which involves SUMO pathway and Rad18 but not Rad18-mediated ubiquitination of PCNA. We therefore propose that poln is differentially regulated in response to DNA insults or to intrinsic replication fork barriers to maintain genome stability. The protein Rad18 serves as a common regulator for these distinct pathways.

\section{Methods}

Cell lines. Normal (MRC5-V1) and XPV (XP30RO) SV-40 immortalized fibroblasts (kind gift from A. Lehmann and J. E. Cleaver, respectively) were maintained in Minimal Eagle Medium (MEM Glutamax; Gibco) supplemented with 10\% fetal calf serum, $100 \mathrm{U} \mathrm{ml}^{-1}$ penicillin and $100 \mu \mathrm{g} \mathrm{ml}^{-1}$ streptomycin. MRC5HisPCNA $^{\mathrm{K} 164 \mathrm{R}}$ cells $^{64}$ (kind gift from A. Lehmann) were grown in the presence of $0.8 \mathrm{mg} \mathrm{ml}^{-1}$ G418. 293FT (Invitrogen), U2OS (kind gift from V. Pennaneach) and HCT116 (kind gift from T. Shiomi) cells were maintained in DMEM (Gibco) supplemented with $10 \%$ fetal calf serum, L-glutamine, non-essential amino acids, sodium pyruvate, $100 \mathrm{U} \mathrm{ml}^{-1}$ penicillin and $100 \mu \mathrm{g} \mathrm{ml}^{-1}$ streptomycin. HCT116-RAD18 ${ }^{-1-}$ cells $^{65}$ were grown in the presence of $300 \mu \mathrm{g} \mathrm{ml}^{-1} \mathrm{G} 418$ and $0.3 \mu \mathrm{g} \mathrm{ml}^{-1}$ puromycin. Cells were cultivated at $37^{\circ} \mathrm{C}$ under $5 \% \mathrm{CO}_{2}$. Construction of stable XP30RO cells expressing WT pol $\eta$ (poln WT) was described elsewhere ${ }^{66}$. XP30RO cells expressing pol $\eta^{\mathrm{K} 163 \mathrm{R}}$ and pol $\eta^{\mathrm{SUMO}}$ were obtained by stable transfection using ExtremGene 9 (Roche), according to the manufacturer's instructions, and selection with $150 \mu \mathrm{g} \mathrm{ml}^{-1}$ of zeocin (Invivogen). WT and mutant cell lines were further grown in presence of $100 \mathrm{\mu g} \mathrm{ml}^{-1}$ zeocin. To generate populations expressing GFP-Rad18, MRC5-V1 cells were transfected with Fugene HD (Promega) and GFP-positive cells were cell sorted and further grown in medium containing $0.8 \mathrm{mg} \mathrm{ml}^{-1} \mathrm{G} 418$ (Gibco).

Plasmids. Pol $\eta$ was expressed using pcDNA.3.1.zeo-.POLH or GFP-C3-POLH plasmids. Mutation of lysine 163 to arginine to generate pol $\eta^{\mathrm{K} 163 \mathrm{R}}$ was done by site-directed mutagenesis according to the manufacturer's instructions (Agilent, pol $\eta$ K163Rs: 5'-cggcagaagagactgttcagagagaggggatgc- $3^{\prime}$; polnK163Ras: 5' gcatcccctctctctgaacagtctcttctgccg- $\left.3^{\prime}\right)$. A mimetic of constitutively SUMOylated poln (poln $\eta^{\mathrm{SUMO}}$ ) was obtained by gene synthesis (Life) by replacing the K163 codon with the sequence of SUMO2 flanked by seven and two glycines upstream and downstream, respectively. This sequence was then cloned in the pcDNA.3.1.zeo- vector. We mutated the C-terminal di-G motif of SUMO2 to alanine to avoid cleavage by the SENPs (SUMOa construct, poln ${ }^{\text {SUMO }}$ G261,262As: $5^{\prime}$-ccaacagcagacggcagctgtctacggtggtg- $3^{\prime} ;$ pol $\eta^{\mathrm{SUMO}}$ G261,262Aas: $5^{\prime}$-caccaccgtag acagctgccgtctgctgttgg- $\left.3^{\prime}\right)$. The SUMOb construct bears an additional mutation of the atg of SUMO2 to generate an eight glycine upstream the SUMO2 sequence

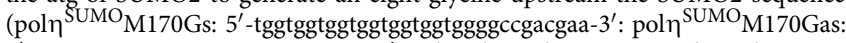
$5^{\prime}$-ttcgtcggccccaccaccaccaccaccacca- $\left.3^{\prime}\right)$. The plasmids expressing the polymerase DEAD mutant (pol $\eta^{\text {polDEAD }}$ ) and GFP-pol $\eta^{1-642}$ were described elsewhere ${ }^{22,67}$ Rad18 was expressed using GFP-C3-RAD18 or pCMV2-HA-RAD18 plasmids. Truncation mutants were obtained by PCR and further cloned in GFP-C3, GFPC3-SV40nls ${ }^{68}$ and pCMV2-HA using the XhoI/BamHI restriction sites added to the primers (forward primer: $5^{\prime}$-GATTACCTCGAGATGGACTCCCTGGCCG AGTCTC-3'; reverse primer for Rad $18^{1-460}: 5^{\prime}$-ATCATGGGATCCTTATGATG CTTCCCAGGCTTCCTCTTCTTC-3'; reverse primer for Rad18 $8^{1-409}$ : $5^{\prime}$-ATCA TGGGATCCCTAGGAGTCCAGCTTTGATTGAGAAAAGTG-3 ${ }^{\prime}$. All aminoacid substitutions were done by site-directed mutagenesis $\left(\operatorname{Rad} 18^{\mathrm{C} 28 \mathrm{~F}} \mathrm{~S}: 5^{\prime}\right.$-atgttga aatactcgaagaaaattccacaccgcagcaaatc- $3^{\prime}$; Rad $188^{\mathrm{C} 28 \mathrm{~F}}$ as: $5^{\prime}$-gatttgctgcggtgtggaattt tcttcgagtatttcaacat- $3^{\prime}$; Rad $18^{\mathrm{C} 207 \mathrm{~F}} \mathrm{~s}: 5^{\prime}$-aagttactaaagtggattgtcctgttttcggggttaacattc- $3^{\prime}$; Rad $18^{\mathrm{C} 207 \mathrm{~F}}$ as: $5^{\prime}$-gaatgttaaccccgaaaacaggacaatccactttagtaactt- $3^{\prime}$ : Rad18 ${ }^{\mathrm{SAP}}{ }^{\mathrm{S}} \mathrm{s}$ : $5^{\prime}$-aaaagagcatggattatctattcaagcaaatgcacaacagctcattaaaaggcacca- $3^{\prime} ; \operatorname{Rad}_{18} 8^{\mathrm{SAP}}$ as: $5^{\prime}$-tggtgccttttaatgagctgttgtgcatttgcttgaatagataatccatgctctttt- $\left.3^{\prime}\right)$. Plasmids expressing His-SUMO1 and His-SUMO3 were a kind gift of Anne Dejean and Mauro Modesti, respectively. Flag-mPIAS1 and Flag-PIAS4 were a gift from Ke Shuai (Addgene plasmids \# 15206 and \# 15208). Flag-SENP1 and Flag-SENP6 were a gift from Edward Yeh (Addgene plasmids \# 17357, \# 17358 and \# 18065).

Cell treatments. For ultraviolet-C irradiation $(254 \mathrm{~nm})$, cells were rinsed in pre-heated PBS and irradiated without any medium at a fluency of $0.65 \mathrm{~J} \mathrm{~m}^{-2} \mathrm{~s}^{-1}$ APH and MG132 (Sigma) stock solutions were at 3 and $4 \mathrm{mM}$, respectively, in DMSO.
siRNAs. siRNAs purchased from Dharmacon were used to transiently downregulate the expression of PIAS1, PIAS4 (smart pool), RAD18 (siRAD18d: $5^{\prime}$-CAUAUUAGAUGAACUGGUAUU-3' ${ }^{\prime}$, siRAD18sp: smart pool; siRad18 3'-UTR: $5^{\prime}$-GTGTGTAAGTACCGATGCAUU-3'), PCNA (5'-GCCGAGAUC UCAGCCAUAUTT- $3^{\prime}$ ) or POLH ( $5^{\prime}$-GAAGUUAUGUCCAGAUCUU- $3^{\prime}$ ). Unspecific siRNAs (siNT) were used as control.

Transfections. Unless otherwise indicated, plasmids were transfected using jetPEI (Polyplus), according to the manufacturer's instructions. Cells were transfected with $30 \mathrm{nM}$ of siRNAs using Interferin (Polyplus) according to the manufacturer's instructions and incubated for $48 \mathrm{~h}$ before treatment. In co-depletion experiments, $15 \mathrm{nM}$ of each specific siRNA was used. siNT $(15 \mathrm{nM})$ was added to ensure a final concentration of $30 \mathrm{nM}$ when required. HCT116 cells were transfected with calcium phosphate. For analysis of SUMOylation by denaturing Ni pull-down, 293FT cells were seeded in $60 \mathrm{~mm}$ dishes 1 day before plasmid transfection $(1 \mu \mathrm{g}$ of pcDNA-POLH or GFP-POLH $+2 \mu \mathrm{g}$ of His or His-SUMO $\pm 1 \mu \mathrm{g}$ of GFP-RAD18 or Flag- PIAS or Flag-SENP). Stable XP30RO-derived cell lines were seeded in $100 \mathrm{~mm}$ dishes and transfected with $7 \mu \mathrm{g}$ of His or His-SUMO3 $24 \mathrm{~h}$ before treatment. In depletion experiments, cells were transfected with siRNAs the day after seeding and further incubated $24 \mathrm{~h}$ before plasmid transfection. Plasmids were allowed to express for $24 \mathrm{~h}$. Alternatively, co-transfection of siRNAs and plasmids were performed by calcium phosphate $48 \mathrm{~h}$ before harvesting. For denaturing GFP-trap, 293FT cells were transfected with $1 \mu \mathrm{g}$ of plasmids expressing GFP, GFP-poln ${ }^{\mathrm{WT}}$ or GFP-poln ${ }^{\mathrm{K} 163 \mathrm{R}}$ and $2 \mu \mathrm{g}$ of HA-SUMO2. For immunoprecipitation experiments, 293FT cells were transfected with $2 \mu \mathrm{g}$ of each of the indicated plasmids $24 \mathrm{~h}$ before harvesting.

Denaturing Ni pull-down. Cells were lysed in $500 \mu$ lof urea buffer (8 M urea and $20 \mathrm{mM}$ imidazole in PBS) supplemented with $20 \mathrm{mM} \mathrm{N}$-ethylmaleimide (NEM, Sigma) at room temperature and sonicated for $15 \mathrm{~s}$ with $30 \%$ amplitude (Vibracell, Bioblock Scientific). Extracts were centrifuged at $16,000 \mathrm{~g}$ for $10 \mathrm{~min}$ at $15^{\circ} \mathrm{C} .50 \mu$ of supernatant was kept as input fraction and boiled for $10 \mathrm{~min}$ in $2 \times$ Laemmli buffer. Samples were incubated with nickel beads (His60 Ni Superflow resin, Clontech) for $45 \mathrm{~min}$ at room temperature on a wheel. Beads were washed four times for $5 \mathrm{~min}$ in $1 \mathrm{ml}$ urea buffer. Proteins were eluted by boiling for $10 \mathrm{~min}$ in $2 \times$ Laemmli buffer with $30 \mathrm{mM}$ EDTA and analysed by western blot.

Denaturing GFP-trap. Purification of GFP-pol $\eta$ in stringent denaturing conditions was performed according to Chromotek's application note on ubiquitination of GFP-tagged proteins. Cells were lysed in GFP-trap lysis buffer $(50 \mathrm{mM}$ Tris-HCl pH 7.5, $150 \mathrm{mM} \mathrm{NaCl}, 1 \mathrm{mM}$ EDTA, $0.5 \%$ Triton $\times 100,20 \mathrm{mM}$ NEM, antiproteases Complete EDTA-free Roche) for $20 \mathrm{~min}$ on ice. Samples were sonicated twice for $10 \mathrm{~s}$ at $29 \%$ amplitude and cleared by centrifugation for $5 \mathrm{~min}$ at $9,500 \mathrm{~g}$ at $4{ }^{\circ} \mathrm{C}$. Supernatants were incubated for $2 \mathrm{~h} 30$ at room temperature on a wheel with $20 \mu \mathrm{l}$ of GFP-trap agarose beads (Chromotek). Beads were washed once with GFP-trap dilution buffer (10 mM Tris-HCl pH 7.5, $150 \mathrm{mM} \mathrm{NaCl}$, $0.5 \mathrm{mM}$ EDTA, $20 \mathrm{mM}$ NEM and antiproteases), three times with stringent washing buffer ( $8 \mathrm{M}$ urea, $1 \%$ SDS in PBS) and once with $1 \%$ SDS in PBS. Bound proteins were eluted by boiling for $10 \mathrm{~min}$ in $2 \times$ Laemmli buffer.

Immunoprecipitation. Cells were lysed in NETN buffer ( $50 \mathrm{mM}$ Tris- $\mathrm{HCl} \mathrm{pH} 7.5$, $150 \mathrm{mM} \mathrm{NaCl}, 1 \mathrm{mM}$ EDTA, $0.5 \% \mathrm{NP} 40$, antiproteases) for $30 \mathrm{~min}$ on ice and sonicated twice at $29 \%$ for $10 \mathrm{~s}$. Samples were cleared by centrifugation at $9,300 \mathrm{~g}$ for $5 \mathrm{~min}$ at $4{ }^{\circ} \mathrm{C}$. Immunoprecipitations were performed with $1 \mu \mathrm{g}$ of antibodies (Bethyl rabbit anti-poln \#A301-230A, Sigma mouse anti-Flag-M2 \#F4049 or Santa Cruz mouse anti-HA F-7 \#sc-7392) for $3 \mathrm{~h}$ at $4^{\circ} \mathrm{C}$ on a wheel followed by $1 \mathrm{~h} 30$ incubation in presence of sepharose-protein A beads (GE Healthcare). Beads were extensively washed in $\mathrm{NETN}$, with $300 \mathrm{mM} \mathrm{NaCl}$ for the final wash, and denatured in $2 \times$ Laemmli.

iPOND. The iPOND experiment was performed as described elsewhere ${ }^{51}$ with minor modifications. Briefly, $10^{8}$ cells were pulse-labelled with $10 \mu \mathrm{M}$ EdU (Invitrogen) for $10 \mathrm{~min}$. Immediately after the pulse or after a $1 \mathrm{~h}$ chase in fresh medium supplemented with $10 \mu \mathrm{M}$ thymidine (Sigma), cells were crosslinked with $1 \%$ formaldehyde (Sigma) in PBS for $15 \mathrm{~min}$ at room temperature under gentle agitation. Crosslink was stopped by addition of $125 \mathrm{mM}$ glycine for $5 \mathrm{~min}$. Cells were harvested by scrapping and washed in ice-cold PBS. Pellets were permeabilized in PBS with $0.5 \%$ Triton $\times 100$ for $30 \mathrm{~min}$ at room temperature. Biotinazide (Molecular Probes) was conjugated to EdU by click chemistry for $2 \mathrm{~h}$ in click reaction buffer $\left(10 \mathrm{mM}\right.$ sodium-L-ascorbate, $10 \mu \mathrm{M}$ biotin-azide, $2 \mathrm{mM} \mathrm{CuSO}_{4}$ in PBS). Cells were lyzed in iPOND lysis buffer (10 mM Hepes- $\mathrm{NaOH} \mathrm{pH} 7.9$, $100 \mathrm{mM} \mathrm{NaCl}, 2 \mathrm{mM}$ EDTA, $1 \mathrm{mM}$ EGTA, $1 \mathrm{mM}$ PMSF, 0.2\% SDS, $0.1 \%$ sarkozyl, antiproteases) and sonicated on a Bioruptor device (30 cycles of $30 \mathrm{~s}$ on $/ 30 \mathrm{~s}$ off at the highest setting). Solubilized chromatin was retrieved by centrifugation at $16,000 \mathrm{~g}$ for $10 \mathrm{~min}$ and supernatant was further incubated overnight with magnetic streptavidin beads (Dynabeabs MyOne Streptavidine C1, Invitrogen). Beads were washed once in lysis buffer, once in $500 \mathrm{mM} \mathrm{NaCl}$ and twice in lysis buffer. Proteins were eluted by boiling in $1 \times$ Laemmli buffer at $95^{\circ} \mathrm{C}$ for $30 \mathrm{~min}$. 
Western blot. For whole-cell extract preparation, cells were lysed in SDS lysis buffer (50 mM Tris pH7.5, $20 \mathrm{mM} \mathrm{NaCl}, 10 \mathrm{mM} \mathrm{MgCl} 2,0.1 \%$ SDS, anti-proteases) supplemented with benzonase for $10 \mathrm{~min}$ at room temperature, as previously described ${ }^{32}$. Proteins were quantified with Bradford assay. Proteins were separated on 8 or $15 \%$ acrylamide SDS-polyacrylamide gel electrophoresis. Membranes were blotted with antibodies directed the following proteins: $\beta$-actin (mouse AC-15, Sigma \#A5441, 1/10,000), Flag (mouse M2, Sigma \#F4049, 1/1,000), GFP (mouse, Roche \#11814460001, 1/1,000), histone H2B (rabbit V119, Cell Signaling \#8135, $1 / 1,000$ ), histone H4 (mouse, Abcam \#ab31830, 1/1,000), HA (mouse HA.11 16B12, Covance \#MMS-101R, 1/1,000), 6x-His tag (mouse \#631212, Clontech, 1/5,000), PCNA (mouse PC10, Santa Cruz \#sc-56, 1/4,000), Ub-PCNA Lys164 (rabbit D5C7P, Cell Signaling \#13439, 1/1,000), PIAS1 (rabbit, Epitomics \#2474, 1/5,000), PIAS4 (rabbit, ProteinTech \#14242-1-AP, 1/1,000), pol $\delta$-p125 (goat C-20, Santa Cruz \#sc-8797, 1/1,000), poln (rabbit, Abcam \#ab17725, 1/1,000; rabbit H-300, Santa Cruz \#sc-5592, 1/2,000; mouse B-7, Santa Cruz \#sc-17770, 1/500; rabbit, Bethyl \#A301-231A, 1/1,000), Rad18 (mouse, Abcam \#ab57447; rabbit, Bethyl \#A301-340A, 1/2,000), RPA32 (mouse, Calbiochem \#NA19L, 1/5,000). Uncropped images for the most relevant blots are shown in Supplementary Fig. 11.

Immunofluorescence. For analysis of pol $\eta$ foci, cells were pre-extracted in CSK100 buffer ( $100 \mathrm{mM} \mathrm{NaCl}, 300 \mathrm{mM}$ sucrose, $3 \mathrm{mM} \mathrm{MgCl}_{2}, 10 \mathrm{mM}$ Pipes $\mathrm{pH}$ 6.8, $1 \mathrm{mM}$ EGTA, $0.2 \%$ Triton $\mathrm{x} 100$, antiproteases) for $5 \mathrm{~min}$ on ice under gentle agitation. Cells were fixed in $4 \%$ paraformaldehyde for $20 \mathrm{~min}$ and permeabilized in methanol at $-20^{\circ} \mathrm{C}$ for $10 \mathrm{~s}$. Cells were incubated for $1 \mathrm{~h}$ at room temperature with primary antibodies (Santa Cruz H300 rabbit anti-poln $1 / 300+$ Santa Cruz PC10 mouse anti-PCNA 1/500) diluted in IF buffer (3\% BSA, 0.5\% Tween 20 in PBS). Cells were washed three times in PBS and stained for $30 \mathrm{~min}$ with secondary antibodies from Molecular Probes (goat anti-rabbit AF488 1/1,000 + goat antimouse AF594 1/1,000). For analysis of 53BP1 NBs or CENPA detection, cells were directly fixed in $4 \%$ paraformaldehyde and permeabilized for $10 \mathrm{~min}$ in PBS supplemented with $0.5 \%$ Triton $\times 100$. Cells were immunostained with rabbit anti-53BP1 $(1 / 300)+$ mouse anti-cyclin A (1/200) or with mouse anti-CENPA (1/500), all from Abcam (\#ab21083, \#ab16726, \#ab13939). For analysis of RPA foci, cells were pulse-labelled with $10 \mu \mathrm{M}$ EdU for $15 \mathrm{~min}$, extracted with CSK100 and fixed. EdU was detected with the Click-iT EdU Alexa Fluor 488 Imaging kit (Molecular Probes), according to the manufacturer's instructions. Cells were then stained for RPA32 (rabbit anti-RPA32, Bethyl \#A300-244A, 1/2,000, detected with goat anti-rabbit AF594). Coverslips were mounted in fluorescent mounting medium (DAKO) supplemented with DAPI. Images were acquired on an Axio Imager Z1 microscope using the Axio Vision software (Zeiss). Intensity was quantified with ImageJ software.

In situ proximity ligation assay. Cells were pulse-labelled with $10 \mu \mathrm{M}$ EdU for $5 \mathrm{~min}$ before pre-extraction and fixation as described above. PLA with nascent DNA was described elsewhere ${ }^{69}$. Briefly, cells were blocked with $3 \%$ BSA in PBS. Biotin-azide was conjugated to EdU by click chemistry and cells were incubated with primary antibodies against pol $\eta$ and biotin (rabbit anti-pol $\eta 1 / 300$, Santa Cruz H300, and mouse anti-biotin 1/6,000, Jackson ImmunoResearch $\# 200-002-211$ ). PLA and EdU counterstaining were performed according to the manufacturer's instructions using the Duolink In Situ Red kit (Sigma) and goat anti-mouse Alexa Fluor 488 antibody.

In vitro transcription/translation of human poln and TLS assay. In vitro transcription/translation of full-length WT or mutant poln was performed using a TNT-coupled reticulocyte lysate system (Promega) according to the manufacturer's instructions. The expression vector encoding poln was added to the reaction mixture and incubated for $90 \mathrm{~min}$ at $30^{\circ} \mathrm{C}$ in the presence of $\left[{ }^{35} \mathrm{~S}\right]$ methionine. The catalytic activity of the DNA polymerase was analysed by primer extension on a circular single-stranded template (pUC118) and separation of the labelled products on a $20 \%$ polyacrylamide- $7 \mathrm{M}$ urea denaturing gel. Construction of single-stranded plasmids containing a single unique TT-CPD (pUC-CDP.ss) has been extensively described $^{70}$. Primer extension analysis was performed as previously described ${ }^{71}$ using a XP30RO cell extract supplemented with an equal amount of WT or mutated pol $\eta$. Briefly, the reaction mixture $(6.25 \mu \mathrm{l})$ containing $10 \mathrm{fmoles}$ of primed monomodified DNA and $20 \mu \mathrm{g}$ of proteins was incubated $20 \mathrm{~min}$ at $37^{\circ} \mathrm{C}$ in $50 \mathrm{mM}$ Hepes- $\mathrm{KOH}$ (pH 7.8), $7 \mathrm{mM} \mathrm{MgCl} 2,1 \mathrm{mM}$ DTT, $4 \mathrm{mM}$ ATP, $500 \mu \mathrm{M}$ of dNTPs, $40 \mathrm{mM}$ creatine phosphate, $100 \mathrm{mg}$ per $\mathrm{ml}$ creatine kinase. The reaction was stopped by adding an equal volume of proteinase $\mathrm{K}$-SDS ( $4 \mathrm{mg} \mathrm{ml}^{-1}-2 \%$ ) and incubated for $30 \mathrm{~min}$ at $37^{\circ} \mathrm{C}$. Purified replication products were further digested with EcoRI and PvuII restriction enzymes and analysed by electrophoresis on a polyacrylamide-7 M urea denaturing gel. Radiolabelled products were visualized and quantified after phophorimaging (Typhoon FLA9500) using the ImageQuant TL software.

Data availability. The data that support the findings of this study are available from the corresponding authors upon request.

\section{References}

1. Sale, J. E., Lehmann, A. R. \& Woodgate, R. Y-family DNA polymerases and their role in tolerance of cellular DNA damage. Nat. Rev. Mol. Cell Biol. 13, 141-152 (2012).

2. Masutani, C., Kusumoto, R., Iwai, S. \& Hanaoka, F. Mechanisms of accurate translesion synthesis by human DNA polymerase eta. EMBO J. 19, 3100-3109 (2000).

3. Yoon, J. H., Prakash, L. \& Prakash, S. Highly error-free role of DNA polymerase eta in the replicative bypass of UV-induced pyrimidine dimers in mouse and human cells. Proc. Natl Acad. Sci. USA 106, 18219-18224 (2009).

4. Kannouche, P. L., Wing, J. \& Lehmann, A. R. Interaction of human DNA polymerase eta with monoubiquitinated PCNA: a possible mechanism for the polymerase switch in response to DNA damage. Mol. Cell 14, 491-500 (2004)

5. Bienko, M. et al. Ubiquitin-binding domains in Y-family polymerases regulate translesion synthesis. Science 310, 1821-1824 (2005).

6. Despras, E., Delrieu, N., Garandeau, C., Ahmed-Seghir, S. \& Kannouche, P. L. Regulation of the specialized DNA polymerase eta: revisiting the biological relevance of its PCNA- and ubiquitin-binding motifs. Environ. Mol. Mutagen. 53, 752-765 (2012).

7. Day, T. A. et al. Phosphorylated Rad18 directs DNA polymerase eta to sites of stalled replication. J. Cell Biol. 191, 953-966 (2010).

8. Watanabe, K. et al. Rad18 guides poleta to replication stalling sites through physical interaction and PCNA monoubiquitination. EMBO J. 23, 3886-3896 (2004).

9. Chen, Y. W. et al. Human DNA polymerase eta activity and translocation is regulated by phosphorylation. Proc. Natl Acad. Sci. USA 105, 16578-16583 (2008).

10. Gohler, T., Sabbioneda, S., Green, C. M. \& Lehmann, A. R. ATR-mediated phosphorylation of DNA polymerase eta is needed for efficient recovery from UV damage. J. Cell Biol. 192, 219-227 (2011).

11. Davis, E. J. et al. DVC1 (C1orf124) recruits the p97 protein segregase to sites of DNA damage. Nat. Struct. Mol. Biol. 19, 1093-1100 (2012).

12. Jung, Y. S., Liu, G. \& Chen, X. Pirh2 E3 ubiquitin ligase targets DNA polymerase eta for $20 \mathrm{~S}$ proteasomal degradation. Mol. Cell. Biol. 30, 1041-1048 (2010).

13. Mosbech, A. et al. DVC1 (C1orf124) is a DNA damage-targeting p97 adaptor that promotes ubiquitin-dependent responses to replication blocks. Nat. Struct. Mol. Biol. 19, 1084-1092 (2012).

14. Bergoglio, V. et al. DNA synthesis by Pol eta promotes fragile site stability by preventing under-replicated DNA in mitosis. J. Cell Biol. 201, 395-408 (2013).

15. Rey, L. et al. Human DNA polymerase eta is required for common fragile site stability during unperturbed DNA replication. Mol. Cell. Biol. 29, 3344-3354 (2009).

16. Naim, V., Wilhelm, T., Debatisse, M. \& Rosselli, F. ERCC1 and MUS81-EME1 promote sister chromatid separation by processing late replication intermediates at common fragile sites during mitosis. Nat. Cell Biol. 15, 1008-1015 (2013).

17. Ying, S. et al. MUS81 promotes common fragile site expression. Nat. Cell Biol. 15, 1001-1007 (2013).

18. Chan, K. L., Palmai-Pallag, T., Ying, S. \& Hickson, I. D. Replication stress induces sister-chromatid bridging at fragile site loci in mitosis. Nat. Cell Biol. 11, 753-760 (2009)

19. Naim, V. \& Rosselli, F. The FANC pathway and BLM collaborate during mitosis to prevent micro-nucleation and chromosome abnormalities. Nat. Cell Biol. 11, 761-768 (2009).

20. Harrigan, J. A. et al. Replication stress induces 53BP1-containing OPT domains in G1 cells. J. Cell Biol. 193, 97-108 (2011).

21. Lukas, C. et al. 53BP1 nuclear bodies form around DNA lesions generated by mitotic transmission of chromosomes under replication stress. Nat. Cell Biol. 13, 243-253 (2011).

22. Kannouche, P. et al. Domain structure, localization, and function of DNA polymerase eta, defective in xeroderma pigmentosum variant cells. Genes Dev. 15, 158-172 (2001).

23. Sirbu, B. M. et al. Analysis of protein dynamics at active, stalled, and collapsed replication forks. Genes Dev. 25, 1320-1327 (2011).

24. Lopez-Contreras, A. J. et al. A proteomic characterization of factors enriched at nascent DNA molecules. Cell Rep. 3, 1105-1116 (2013).

25. Kim, S. H. \& Michael, W. M. Regulated proteolysis of DNA polymerase eta during the DNA-damage response in C. elegans. Mol. Cell 32, 757-766 (2008).

26. Tatham, M. H. et al. Polymeric chains of SUMO-2 and SUMO-3 are conjugated to protein substrates by SAE1/SAE2 and Ubc9. J Biol Chem 276, 35368-35374 (2001).

27. Teng, S., Luo, H. \& Wang, L. Predicting protein sumoylation sites from sequence features. Amino acids 43, 447-455 (2012).

28. Xue, Y., Zhou, F., Fu, C., Xu, Y. \& Yao, X. SUMOsp: a web server for sumoylation site prediction. Nucleic acids research 34, W254-W257 (2006).

29. Bienko, M. et al. Regulation of translesion synthesis DNA polymerase eta by monoubiquitination. Mol Cell 37, 396-407 (2010).

30. Biertumpfel, C. et al. Structure and mechanism of human DNA polymerase eta. Nature 465, 1044-1048 (2010). 
31. Arlett, C. F., Harcourt, S. A. \& Broughton, B. C. The influence of caffeine on cell survival in excision-proficient and excision-deficient xeroderma pigmentosum and normal human cell strains following ultraviolet-light irradiation. Mutat. Res. 33, 341-346 (1975).

32. Despras, E., Daboussi, F., Hyrien, O., Marheineke, K. \& Kannouche, P. L. ATR/ Chk1 pathway is essential for resumption of DNA synthesis and cell survival in UV-irradiated XP variant cells. Hum. Mol. Genet. 19, 1690-1701 (2010).

33. Galanty, Y. et al. Mammalian SUMO E3-ligases PIAS1 and PIAS4 promote responses to DNA double-strand breaks. Nature 462, 935-939 (2009).

34. Gibbs-Seymour, I. et al. Ubiquitin-SUMO circuitry controls activated fanconi anemia ID complex dosage in response to DNA damage. Mol. Cell 57, 150-164 (2015).

35. Morris, J. R. et al. The SUMO modification pathway is involved in the BRCA1 response to genotoxic stress. Nature 462, 886-890 (2009).

36. Nakajima, S. et al. Replication-dependent and -independent responses of RAD18 to DNA damage in human cells. J. Biol. Chem. 281, 34687-34695 (2006).

37. Miyauchi, Y., Yogosawa, S., Honda, R., Nishida, T. \& Yasuda, H. Sumoylation of Mdm2 by protein inhibitor of activated STAT (PIAS) and RanBP2 enzymes. J. Biol. Chem. 277, 50131-50136 (2002).

38. Huang, J. et al. RAD18 transmits DNA damage signalling to elicit homologous recombination repair. Nat. Cell Biol. 11, 592-603 (2009).

39. Tateishi, S., Sakuraba, Y., Masuyama, S., Inoue, H. \& Yamaizumi, M. Dysfunction of human Rad18 results in defective postreplication repair and hypersensitivity to multiple mutagens. Proc. Natl Acad. Sci. USA 97, 7927-7932 (2000).

40. Kannouche, P. L. \& Lehmann, A. R. Ubiquitination of PCNA and the polymerase switch in human cells. Cell Cycle 3, 1011-1013 (2004).

41. Terai, K., Abbas, T., Jazaeri, A. A. \& Dutta, A. CRL4(Cdt2) E3 ubiquitin ligase monoubiquitinates PCNA to promote translesion DNA synthesis. Mol. Cell 37, 143-149 (2010).

42. Zhang, S. et al. PCNA is ubiquitinated by RNF8. Cell Cycle 7, 3399-3404 (2008).

43. Bacquin, A. et al. The helicase FBH1 is tightly regulated by PCNA via CRL4(Cdt2)-mediated proteolysis in human cells. Nucleic Acids Res. 41, 65016513 (2013).

44. Tsanov, N. et al. PIP degron proteins, substrates of CRL4Cdt2, and not PIP boxes, interfere with DNA polymerase eta and kappa focus formation on UV damage. Nucl. Acids Res. 42, 3692-3706 (2014).

45. Edmunds, C. E., Simpson, L. J. \& Sale, J. E. PCNA ubiquitination and REV1 define temporally distinct mechanisms for controlling translesion synthesis in the avian cell line DT40. Mol. Cell 30, 519-529 (2008).

46. Hendel, A. et al. PCNA ubiquitination is important, but not essential for translesion DNA synthesis in mammalian cells. PLoS Genet. 7, e1002262 (2011).

47. Krijger, P. H. et al. PCNA ubiquitination-independent activation of polymerase eta during somatic hypermutation and DNA damage tolerance. DNA Repair 10, 1051-1059 (2011).

48. Dungrawala, H. et al. The replication checkpoint prevents two types of fork collapse without regulating replisome stability. Mol. Cell 59, 998-1010 (2015).

49. Kile, A. C. et al. HLTF's ancient HIRAN domain binds 3' DNA ends to drive replication fork reversal. Mol. Cell 58, 1090-1100 (2015).

50. Boyer, A. S., Grgurevic, S., Cazaux, C. \& Hoffmann, J. S. The human specialized DNA polymerases and non-B DNA: vital relationships to preserve genome integrity. J. Mol. Biol. 425, 4767-4781 (2013).

51. Lossaint, G. et al. FANCD2 binds MCM proteins and controls replisome function upon activation of s phase checkpoint signaling. Mol. Cell 51, 678-690 (2014).

52. Tsuji, Y. et al. Recognition of forked and single-stranded DNA structures by human RAD18 complexed with RAD6B protein triggers its recruitment to stalled replication forks. Genes Cells 13, 343-354 (2008).

53. Inagaki, A. et al. Dynamic localization of human RAD18 during the cell cycle and a functional connection with DNA double-strand break repair. DNA Repair 8, 190-201 (2009).

54. Miyase, S. et al. Differential regulation of Rad18 through Rad6-dependent mono- and polyubiquitination. J. Biol. Chem. 280, 515-524 (2005).

55. Watanabe, K. et al. RAD18 promotes DNA double-strand break repair during G1 phase through chromatin retention of 53BP1. Nucl. Acids Res. 37, 2176-2193 (2009).

56. Inagaki, A. et al. Human RAD18 interacts with ubiquitylated chromatin components and facilitates RAD9 recruitment to DNA double strand breaks. PloS ONE 6, e23155 (2011).

57. Hay, R. T. SUMO: a history of modification. Mol. Cell 18, 1-12 (2005).

58. Johnson, E. S. Protein modification by SUMO. Annu. Rev. Biochem. 73, 355-382 (2004).

59. Hendriks, I. A. et al. Uncovering global SUMOylation signaling networks in a site-specific manner. Nat. Struct. Mol. Biol. 21, 927-936 (2014).

60. Bergink, S. et al. Role of Cdc48/p97 as a SUMO-targeted segregase curbing Rad51-Rad52 interaction. Nat. Cell Biol. 15, 526-532 (2013).

61. Nie, M. et al. Dual recruitment of Cdc48 (p97)-Ufd1-Npl4 ubiquitin-selective segregase by small ubiquitin-like modifier protein (SUMO) and ubiquitin in
SUMO-targeted ubiquitin ligase-mediated genome stability functions. J. Biol. Chem. 287, 29610-29619 (2012).

62. Stingele, J., Habermann, B. \& Jentsch, S. DNA-protein crosslink repair: proteases as DNA repair enzymes. Trends Biochem. Sci. 40, 67-71 (2015).

63. Balakirev, M. Y. et al. Wss1 metalloprotease partners with Cdc48/Doal in processing genotoxic SUMO conjugates. Elife 4, e06763 (2015).

64. Niimi, A. et al. Regulation of proliferating cell nuclear antigen ubiquitination in mammalian cells. Proc. Natl Acad. Sci. USA 105, 16125-16130 (2008).

65. Shiomi, N. et al. Human RAD18 is involved in S phase-specific singlestrand break repair without PCNA monoubiquitination. Nucl. Acids Res. 35, e9 (2007).

66. Stary, A., Kannouche, P., Lehmann, A. R. \& Sarasin, A. Role of DNA polymerase eta in the UV mutation spectrum in human cells. J. Biol. Chem. 278, 18767-18775 (2003)

67. Zlatanou, A. et al. The hMsh2-hMsh6 complex acts in concert with monoubiquitinated PCNA and Pol eta in response to oxidative DNA damage in human cells. Mol. Cell 43, 649-662 (2011).

68. Ahmed-Seghir, S. et al. Aberrant C-terminal domain of polymerase eta targets the functional enzyme to the proteosomal degradation pathway. DNA Repair 29, 154-165 (2015).

69. Petruk, S. et al. TrxG and PcG proteins but not methylated histones remain associated with DNA through replication. Cell 150, 922-933 (2012).

70. Napolitano, R. L. \& Fuchs, R. P. New strategy for the construction of singlestranded plasmids with single mutagenic lesions. Chem. Res. Toxicol. 10, 667-671 (1997).

71. Cordonnier, A. M., Lehmann, A. R. \& Fuchs, R. P. Impaired translesion synthesis in xeroderma pigmentosum variant extracts. Mol. Cell. Biol. 19, 2206-2211 (1999).

\section{Acknowledgements}

We are grateful to J.E. Cleaver for XP30RO cells, T. Shiomi for HCT116 RAD18 ${ }^{-/-}$ cells and A. Lehmann for MRC5-HisPCNA ${ }^{\text {K164R }}$ cells. We thank M. Modesti and A. Dejean for the kind gift of His-SUMO plasmids, W. Yang for useful advice on the design of poln ${ }^{\text {SUMO }}$ and R Fuchs for the TT-CPD substrate. We thank C. Garandeau and A. Cahn for technical assistance. We are indebted to C. Ribeyre and A. Constantinou for their help with the iPOND experiments and to Y. Lecluse and P. Rameau for cell sorting. We thank J.H. Guervilly, P.H. Gaillard, V. Naim and S. Aoufouchi for fruitful discussions. The PLK laboratory is supported by La Ligue Nationale contre le Cancer (Equipe labellisée). This work was supported by grant from INCa PLBio-2010, INCaDGOS-INSERM 6043, ARC foundation (grant2014) and Gefluc. E.D. received fellowship from Agence Nationale de la Recherche ( $\mathrm{N}^{\circ}$ ANR-09-PIRI-001) and Institut National du Cancer (INCa PLBio-2010). N.D. received fellowships from the ARC foundation.

\section{Author contributions}

E.D. and P.L.K. designed the experiments. E.D. performed and analysed most of the experiments. M.S. constructed and analysed the mutants of the predicted SUMO sites. C.P. constructed the Rad18 mutants. N.D. performed preliminary experiments on 53BP1 NBs after Rad18 depletion. A.M.C. designed and performed the in vitro replication assays. E.D. prepared the draft figures. E.D. and P.L.K. prepared the manuscript. All authors approved the final manuscript.

\section{Additional information}

Supplementary Information accompanies this paper at http://www.nature.com/ naturecommunications

Competing financial interests: The authors declare no competing financial interests.

Reprints and permission information is available online at http://npg.nature.com/ reprintsandpermissions/

How to cite this article: Despras, E. et al. Rad18-dependent SUMOylation of human specialized DNA polymerase eta is required to prevent under-replicated DNA Nat. Commun. 7, 13326 doi: 10.1038/ncomms13326 (2016).

Publisher's note: Springer Nature remains neutral with regard to jurisdictional claims in published maps and institutional affiliations.

This work is licensed under a Creative Commons Attribution 4.0 International License. The images or other third party material in this article are included in the article's Creative Commons license, unless indicated otherwise in the credit line; if the material is not included under the Creative Commons license, users will need to obtain permission from the license holder to reproduce the material. To view a copy of this license, visit http://creativecommons.org/licenses/by/4.0/

(C) The Author(s) 2016 